\title{
The impact of nanoparticle protein corona on cytotoxicity, immunotoxicity and target drug delivery
}

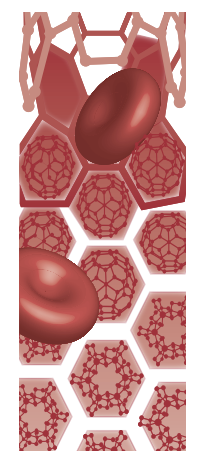

In a perfect sequence of events, nanoparticles (NPs) are injected into the bloodstream where they circulate until they reach the target tissue. The ligand on the NP surface recognizes its specific receptor expressed on the target tissue and the drug is released in a controlled manner. However, once injected in a physiological environment, NPs interact with biological components and are surrounded by a protein corona (PC). This can trigger an immune response and affect NP toxicity and targeting capabilities. In this review, we provide a survey of recent findings on the NP-PC interactions and discuss how the PC can be used to modulate both cytotoxicity and the immune response as well as to improve the efficacy of targeted delivery of nanocarriers.

First draft submitted: 31 July 2015; Accepted for publication: 29 October 2015; Published online: 11 December 2015

Keywords: immune response $\bullet$ nano-bio interface $\bullet$ nanomedicine $\bullet$ nanoparticles $\bullet$ protein corona $\bullet$ targeting $\bullet$ toxicity

Nanomedicine is the field of science devoted to the medical application of nanoparticles (NPs). Recent years have seen a surge in the development of nanomaterials as therapeutic and diagnostic agents, paralleled by major advances in the development of nano-sized delivery systems for targeted drug administration. In this scenario, it is important to understand the interactions occurring at the interface between NPs and biological components in order to predict the fate of injected NPs. Once NPs interact with biological fluids and come into contact with tissues, they are exposed to active biomolecules that form a 'crown' (corona in Latin) around them, thus transforming the bare NP into an NP that has a biological component: the so-called protein corona (PC). The $\mathrm{PC}$ is primarily composed of proteins that are the basis of most of the investigations conducted so far in this field [1-3]. The presence of other biomolecules such as sugars, nucleic acids and lipids is expected but so far little studied [4,5]. The first studies on the interactions between
NPs and plasma proteins were conducted between 1996 and 2000 [6-8], but it was the group of Dawson that first introduced the NP-PC complex concept [3]. The synthetic identity of the NP was replaced by a new biological identity, namely, the NP-PC complex (Figure 1) and as a consequence, researchers are now starting to consider NP-PC complexes as the new NPs. During their journey in the body NPs are subjected to significant changes in their physicochemical properties and in their biological identity. Therefore, the characterization of the properties of NP-PC complexes has become a mandatory step in an experimental plan involving the use of NPs. On the other hand, the physicochemical characterization of bare NPs before exposure to body fluids remains crucial to reveal the correlations between the properties of NPs and PC composition (Figure 1). During the recent years, a large number of studies have been devoted to the characterization of NPPC complexes [9-23]. Furthermore, the scientific community is now moving from the
Claudia Corbo*,1,2, Roberto Molinaro', Alessandro Parodi ${ }^{1}, 2$, Naama E Toledano Furman ${ }^{1}$, Francesco Salvatore ${ }^{3}$ \& Ennio Tasciotti ${ }^{1}$

'Department of Regenerative Medicine, Houston Methodist Research Institute, 6670 Bertner Avenue, 77030 Houston, TX, USA

2Fondazione SDN, Via Gianturco 113, 80143 Naples, Italy

${ }^{3}$ CEINGE, Advanced Biotechnology s.c.a.r.l., Via G. Salvatore 486, 80145 Naples, Italy

*Author for correspondence: ccorbo@houstonmethodist.org
Future $\because \because$ Medicine part of 


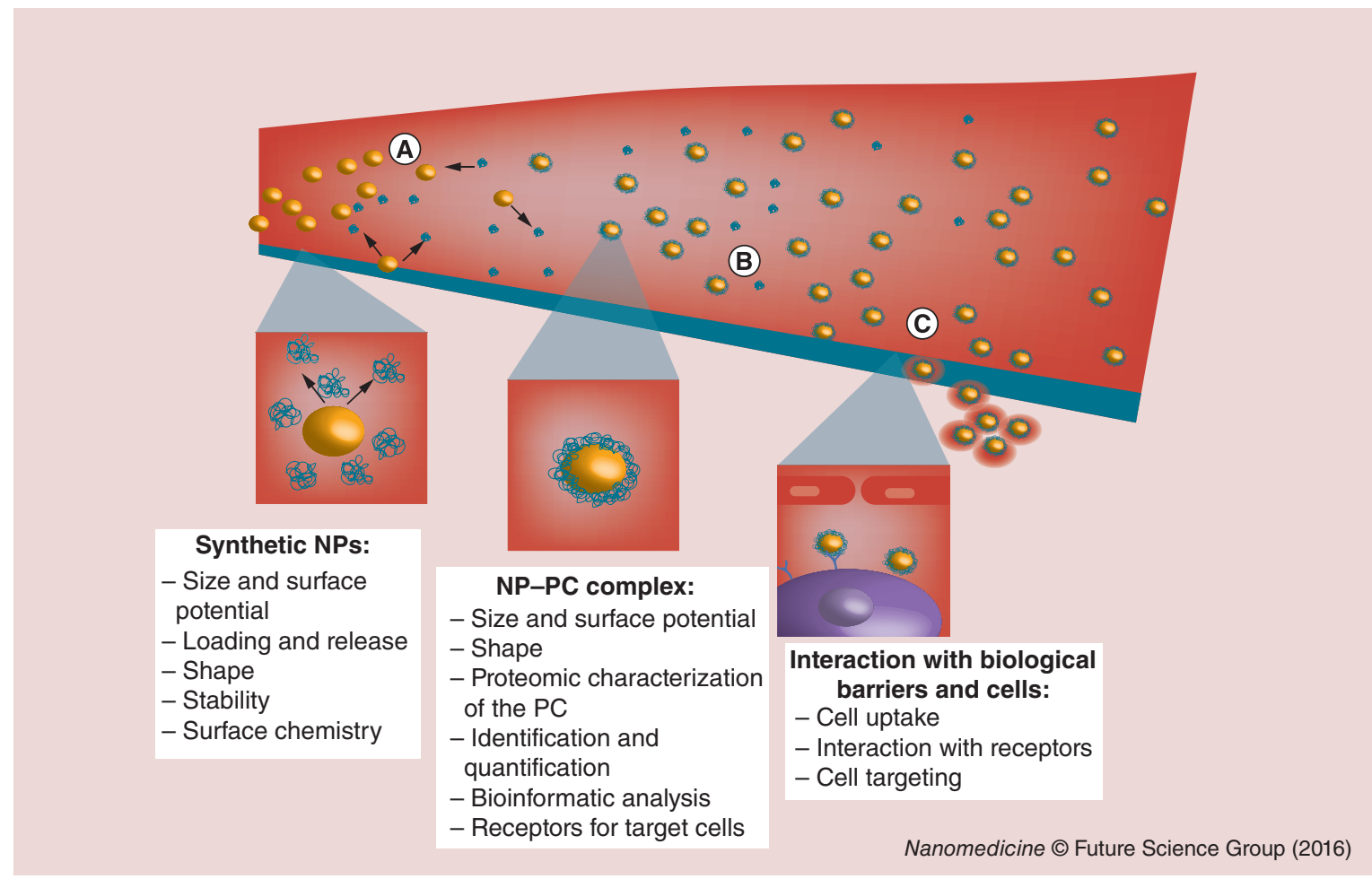

Figure 1. The nanoparticle journey in the body: from synthetic identity to physiological response through biological identity. (A) The bare NP (synthetic identity) that has a specific shape, size and charge is injected into the body. (B) Once exposed to biological fluids, synthetic NPs come into contact with active biomolecules that surround them thus giving rise to the NP-PC complex (biological identity). (C) These NP-PC complexes are responsible for the interaction with biological barriers and cells. The NP can reach the target site using a specific receptor endowed upon them by the PC as part of their new biological identity (physiological response). The experimental steps associated to the study of bare NPs, NP-PC complexes and their physiological behaviors are also reported.

NP: Nanoparticle; PC: Protein corona.

mere evaluation of the impact of the PC on the physical and chemical properties of NPs to the impact on their behavior in physiological systems.

In addition to a discussion on the dynamics of PC formation, its composition and the experimental approaches used, in this review we discuss the most recent advances regarding the impact of the PC on NPs targeting ability, toxicity and immunological recognition.

\section{Dynamics of PC formation}

Time evolution studies on the composition of the PC have demonstrated that the process of NP-PC complex formation is in continuous evolution and that the adsorption of proteins on the surface is mainly governed by affinity interactions of proteins towards the NP surface and by affinity-based protein-to-protein interactions [24]. For example, although blood plasma is constituted by thousands of proteins $(\approx 4000)$ and some of which are more abundant than others [25]), their abundance in the plasma does not correspond to their abundance in the PC [26-30]. Moreover, the affin- ity-based competition between proteins for adsorption on the NP surface is responsible for the changes in the PC composition over time [31]. Based on the exchange time of its composition, the $\mathrm{PC}$ is classified into hard and soft (Figure 2). The hard corona is considered the first tightly bound layer of proteins that has a long exchange time (many hours), while the soft corona is represented by the second layer of proteins (not directly bound to the NP) that undergoes fast exchanges over time (seconds or minutes) [11]. The proteins adsorbed on NPs are considered to be in a continuous flux of desorption/adsorption mainly controlled by the so-called 'Vroman effect' [32] as the group of Vroman observed this phenomenon at the plasma-solid interface in 1962 [33]. According to this 'effect', an initially attached protein can, at any time, desorb from a NP and be replaced by a different one with major affinity. This substantially changes the PC composition while the amount of adsorbed proteins remains relatively constant. In theory, proteins that are more abundant in the biological fluids are the first to be adsorbed during the initial phase, after which 
they are replaced by proteins of lower abundance but higher affinity that remain around the NP for a longer time $[3,34,35]$. This model has been widely discussed and implies the existence of a highly dynamic PC formed over time. More recently, Tenzer et al. described the early evolution and impact of the NPPC complex. They demonstrated that an interaction between NP surface and plasma proteins is already established at $0.5 \mathrm{~min}$ in all the formulations under investigation (silica and polystyrene NPs of various sizes and surface functionalization) [36]. They also found that the composition of the generated PC did not change qualitatively but only quantitatively over time [36], thus showing results in contrast with previous reports discussed above. These findings led to the introduction of a novel model of PC formation, which implies new binding kinetics independent from the Vroman effect [37] (Figure 3).

\section{Composition of the PC}

The PC can be considered unique for each given nanomaterial and even in the case of NPs constituted by the same material, it greatly depends on the physicochemical properties of NPs. Size [38], shape [39] and surface charge $[38,40-42]$, together with the surface modifica- tion [22] are key factors in determining the composition of the PC.

The characteristics of the biological environment also play a determinant role in the formation of a PC: the type of plasma (e.g., human or murine), incubation time, temperature, $\mathrm{pH}$ and the physiological state of the plasma (alterations due to disease/medical conditions) [36,42-44] may also affect the protein adsorption on the NP surface.

Despite this great variability, a similar subset of about 125 proteins has been shown to be adsorbed on various nanomaterials in different amounts when incubated in plasma [2]. These proteins are involved in the same cellular processes, namely, complement activation, pathogen recognition and blood coagulation. Despite this similarity in function, they have a different physiological impact on NPs depending on their material $[2,45]$. Among these, immunoglobulin G, serum albumin, fibrinogen, clusterin and apolipoproteins are generally present in the PC of most analyzed NPs after exposure to plasma $[2,46]$.

Since the majority of NPs are intended for intravenous administration [47], most of the studies in the current literature are devoted to the characterization of the PC adsorbed on NPs after incubation in

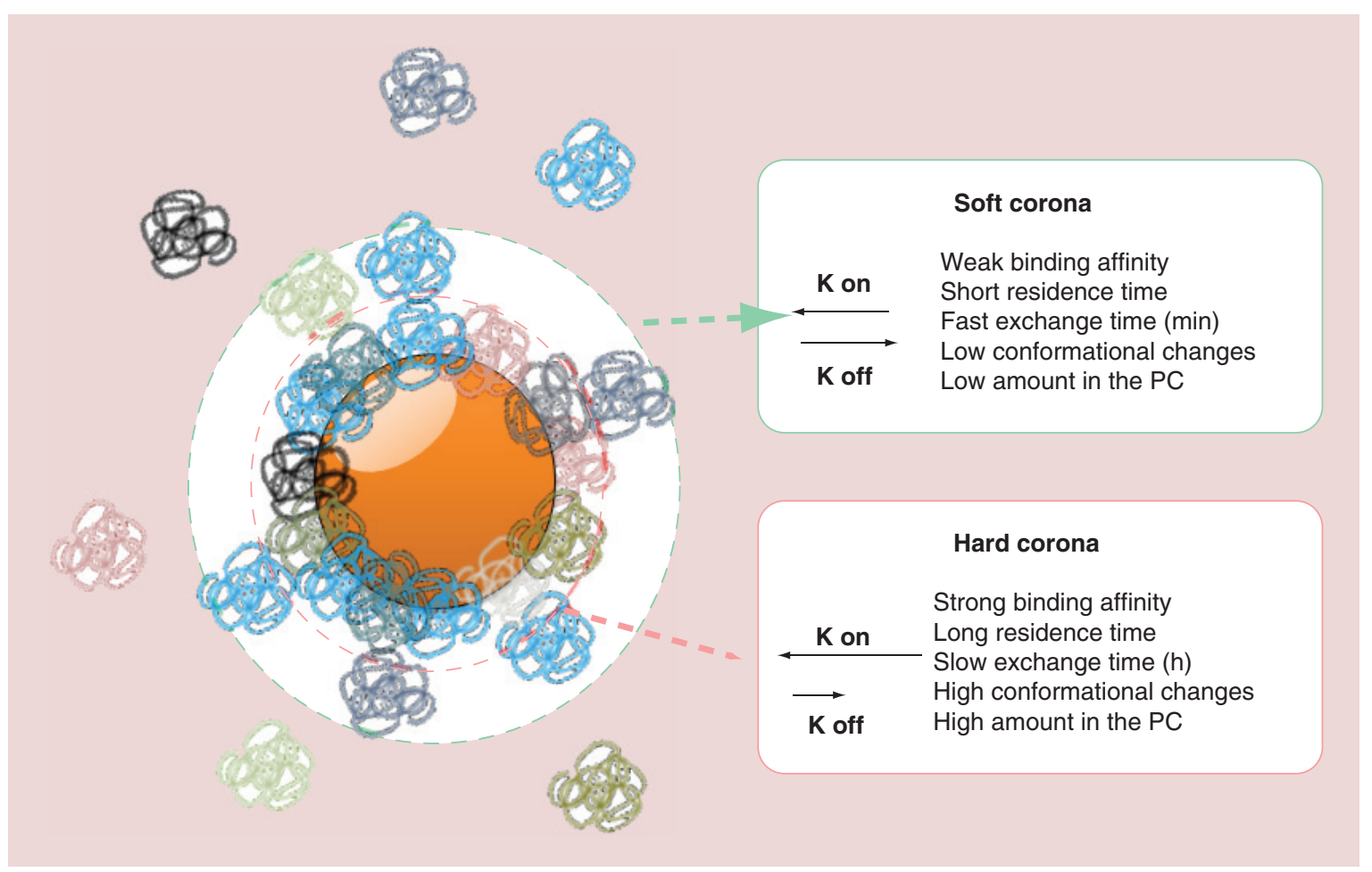

Figure 2. Nanoparticle-protein corona complexes: characteristics of hard and soft coronas. The protein corona represents the biological entity of a nanoparticle. Hard corona proteins are directly adsorbed on the nanoparticle surface due to their strong binding affinity. These proteins also have a slow exchange time. Soft corona proteins associate with the hard corona via weak protein-protein interactions, thus showing a short residence time around the nanoparticle and a fast exchange time. The objects are not drawn in scale.

PC: Protein corona. 


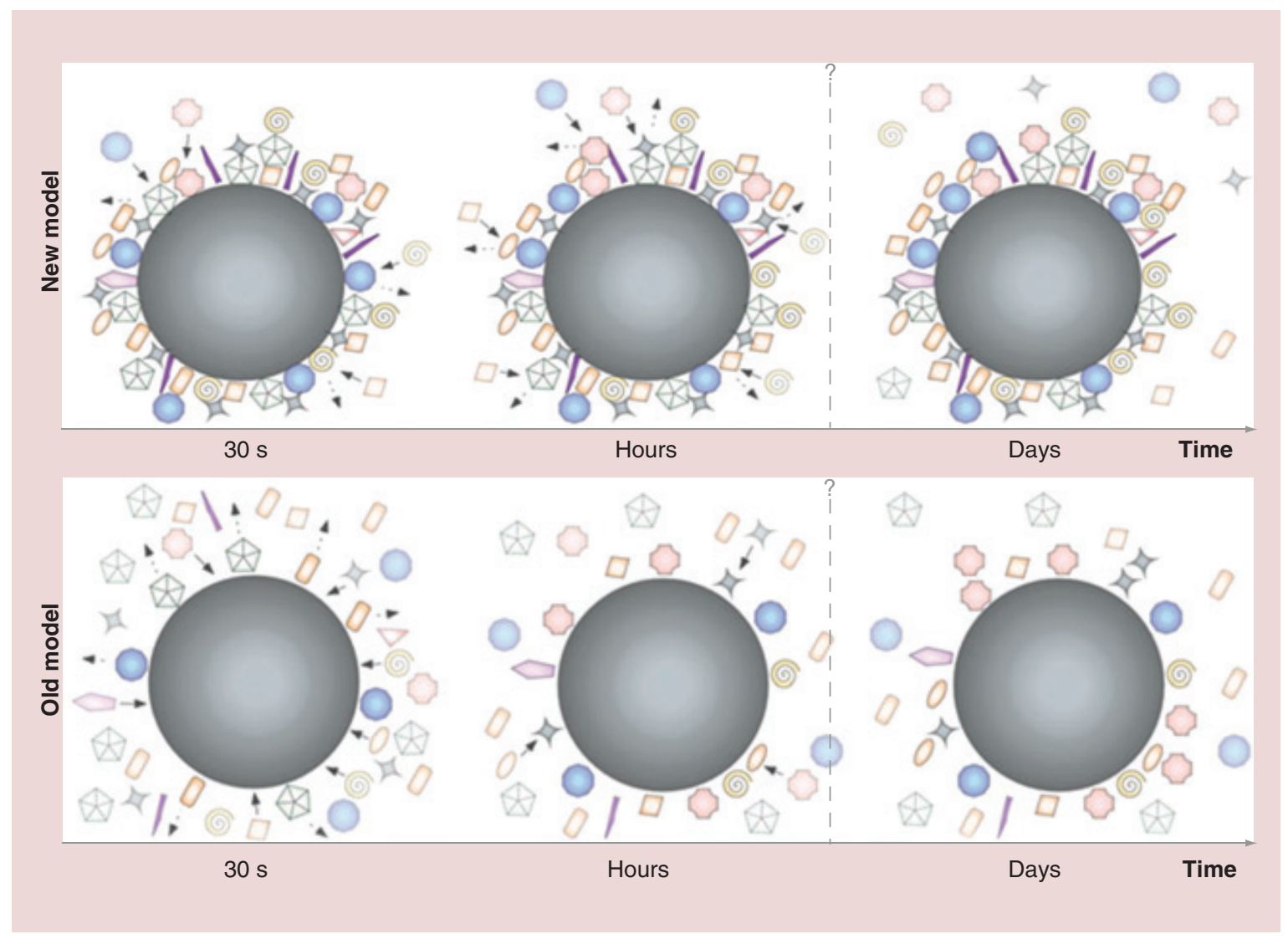

Figure 3. Formation of the protein corona: the old versus the new model. During the very early phase: a highly complex corona is established (new). A corona of low complexity evolves slowly (old). During the late phase: the protein corona composition remains stable and shows quantitative rather than qualitative changes and binding kinetics dependent and independent of the Vroman effect (new). A highly dynamic protein corona changes significantly over time, controlled by the Vroman effect (old). The objects are not drawn to scale. Reproduced with permission from [37].

plasma [19,48-50]. Similarly, information about the nano-plasma interface and the effects it may have on the biocompatibility and efficacy of nanotherapeutics is now becoming available [51,52].

However, when other administrative routes are used, NPs are subjected to interactions with biomolecules of other biological fluids before reaching the plasma. For example, inhaled NPs are first exposed to lung fluid [53], which has a very different composition than blood plasma [54]. A first PC, rich in surfactant proteins and other biomolecules, is generated around the NPs in the lungs [55-57]. This is then displaced by a new corona as soon as the NPs enter the bloodstream [9]. Instead, NPs administrated via oral ingestion are subjected to contact with saliva and then with fluids of the gastrointestinal tract: an environment characterized by a low $\mathrm{pH}$ and the presence of enzymes that may hinder the bioavailability of NPs. Little information is available about the interactions of NPs with the biological milieu of the GI tract [58]. It is becoming clear that a deeper understanding of the role of PC generated in biological fluids other than blood plasma is needed.

\section{Experimental approaches used to characterize} the PC

Many studies have revealed the identity [21,35,38,39,42,59-61] and, more recently, also the quantity $[28,36,62-64]$ of the proteins in the PC using proteomics-based approaches coupled with MS. In a typical experimental plan, NPs are incubated in a biological fluid that ideally should replicate the features of the in vivo biological milieu. After incubation, the NPs are recovered by centrifugation, ultrafiltration $[60,65]$ or, more recently, by a combination of size exclusion chromatography and ultrafiltration [66], and extensively washed to avoid contamination of nonbound proteins. Finally, the adsorbed proteins are eluted from the NP surface and analyzed by two different methods: gel-based or gel-free proteomics [67]. The first implies the separation of proteins through mono or bidimensional sodium dodecyl sulfate electrophoresis followed by in situ digestion and identification by MS $[9,36,66]$. In the gel-free proteomic approaches, instead, complex peptide mixtures are separated using last generation mass spectrometers during the chromatography step that precedes the identifica- 
tion by MS. Among the latters, label-free MS [68] is becoming the gold standard procedure with which to obtain simultaneously a quantitative and qualitative analysis of PC components [64,69-71] thanks to its benefits that include a low number of steps in the protocol and high reproducibility.

\section{Do in vitro models of the PC reproduce the physiological complexity?}

Despite the progresses made in the field of NP-PC, the majority of the in vitro studies seem to be only partially relevant from a biological point of view because the incubation of NPs inadequately replicates the conditions of an intact biological system. The most widely used in vitro models of the PC are based on a single protein $[72,73]$, usually bovine serum albumin, or plasma in different variations and/or concentrations [4,71].

These types of models oversimplify the studies and cannot serve as a reliable indicator of the much more dynamic and complex in vivo scenario.

Once in the body, NPs traverse various compartments that have different protein concentrations/compositions, $\mathrm{pH}$ values, ionic concentrations and temperatures [74]. Moreover, injected NPs are subjected to blood flow, the velocity of which is another parameter that dynamically changes depending on the environment (e.g., aorta $60 \mathrm{~cm} \mathrm{~s}^{-1}$ vs tumors $0.1 \mathrm{~mm} \mathrm{~s}^{-1}$ ) [52]. Thus, despite many good attempts to simulate the biological systems, in vitro experiments lack several dynamic parameters that exist in vivo and are hard to reproduce. The lack of similarities between these two models could explain why NPs that seem promising in vitro are less promising in preclinical trials.

On the other hand, in vivo experiments are complicated by the fact that NPs cannot be readily recovered once they are injected in animals for protein adsorption analysis. Moreover, the biological identities adsorbed on the NPs in mice and humans could be different from one another [75]. However, several examples of in vivo experiments have been reported.

Recently, Hadjidemetriou et al. [66] investigated in vivo PC formation on commercially available liposomes that are used in the clinical setting (i.e., the anticancer agent Doxil). In particular, they compared in vivo and in vitro PCs in terms of morphology, function and composition. The results revealed that the two PCs differ in morphology: electron microscopy imaging showed that liposomes incubated in plasma in vitro create fibrillar structures, whereas liposomes retrieved after in vivo systemic administration did not. Moreover, the composition of the in vivo $\mathrm{PC}$ was more complex, in terms of variety of molecular species adsorbed, than the in vitro PC. Finally, both in vitro and in vivo PCs affect the targeting capabilities of NPs, thereby decreasing cellular internalization. However, the impact of the in vivo PC was weaker [66].

Sakulkhu and collaborators [62] compared the in vivo and in vitro PCs of superparamagnetic iron oxide NPs (SPIONs), by exploiting the magnetic properties of these NPs to extract them from rat sera after in vivo injection. Even in this case, the results indicated strong differences between the in vivo and in vitro experiments in terms of $\mathrm{PC}$ composition and relative protein amounts. Taken together, the results of this subsection confirm the need to carefully consider the data acquired so far from in vitro studies, and to test their reproducibility in vivo, when possible.

\section{Impact of the PC on the targeting capability of NPs}

Over the past decade, various nanomaterials have been designed for delivery of drugs [76], DNA [77] and imaging agents [78]. These nanocarriers were designed in an attempt to: increase drug bioavailability and avoid drug inactivation, which is particularly important in the case of poorly soluble compounds (i.e., paclitaxel) [79], and in the case of macromolecules sensitive to degradation by blood proteases/peptidases or nucleases, (i.e., proteins/peptides or DNA/RNAbased therapeutics) [80]; minimize side-effects due to a nonspecific body distribution of the drug and to the high amount of drug commonly used [81]; and selectively deliver the payload to the affected area, thereby increasing its tissue accumulation [82]. While the firstgeneration nanocarriers, such as micelles, polyethylene glycol (PEG)-modified liposomes and polymeric NPs fully addressed the first two points, thereby increasing the pharmacokinetics and tolerability of nanoformulate drugs [83,84], the second-generation nanocarriers exploit active targeting strategies to ensure tissuespecific delivery [85]. These approaches are based on the functionalization of the carrier surface with active targeting molecules, (e.g., ligands for cell membrane receptors) [86], monoclonal antibodies [87] and aptamers [88]. Several receptor systems, are overexpressed on the cell surface in such disease conditions as inflammation and cancer [89]. The outcome of the aforementioned strategies has had a high impact on both pharmaceutical research and in the clinical setting. In addition, numerous nanotechnology-based platforms that have the potential to result in more effective and safe therapies have been developed or are currently in development [90,91]. Various carrier functionalizations aimed at improving cellular/tissue targeting and overcoming biological barriers have already been exhaustively reviewed [92-98], and will not be further discussed in this article. Herein, we discuss whether and how the PC affects the interaction between a NP (functional- 
ized or not) and its cellular target, as well as the general mechanisms of that interaction. In the recent years, much attention has focused on the biological identity of NPs [9]. As reported previously, the PC strongly affects the fate and biological impact of NPs, as well as their therapeutic and pathophysiological effects $[99,100]$. It is now evident that the in vivo localization of a nanoplatform ultimately depends on the identity of the PC around its surface, rather than on its physicochemical properties [101], which instead are strong determinants of the composition of the PC [102]. The role of the PC in particle-targeting is still controversial. For example, Salvati et al. [103] recently showed that the targeting abilities of transferrin ( $\mathrm{Tf}$ )-functionalized $\mathrm{SiO}_{2} \mathrm{NPs}$ disappear after their incubation in biological fluids, due to the formation of a PC that prevents Tf from binding its receptor. Consequently, the Tf-related specificity is lost (Figure 4). In addition, Davis et al. [104] demonstrated that Tf-targeted NPs accumulated in tumor tissue independently of the presence of the targeting ligand (Tf), also if the Tf ligand itself provided greater tumor cell uptake. In another study, Varnamkhasti et al. [105] demonstrated how, after incubation in $100 \%$ fetal bovine serum (FBS), aptamer-targeted core-shell chitosan NPs carrying an active metabolite of camptotechin (i.e. SN-38) and nontargeted NPs showed similar cytoxicity activity toward human colon cancer cells HT29. Flow cytometry experiments revealed that the PC induced a reduction in the uptake of the targeted NPs. By contrast, Dai et al. [106] examined the effect of the PC on the targeting ability of a core-shell NP assembled by the layer-by-layer method, conjugated with a humanized A33 monoclonal antibody. They showed that the PC did not significantly affect the targeting ability of antibody-functionalized NPs toward colon cancer cells. Using different concentrations of human serum $(0,10,50$ and $100 \%)$, the authors demonstrated that, although 10 and 100\% human serum induce a different composition of PCs (e.g., 100\% human serum-derived PCs contained most of the proteins, while $10 \%$ human serum-derived PCs had a higher concentration of specific proteins as complement $\mathrm{Clq}$ protein subunits), none of these PCs significantly alter the targeting ability of functionalized NPs [106].

These findings prompt two considerations. First, they illustrate the importance of studying the physicochemical properties of NPs and the experimental conditions in which they will be applied. In fact, even if a simple dispersion, such as phosphate buffer solution, can reveal a specific function, a more complex system that mimics relevant physiological conditions could instead nullify it. In a very elegant study, Mahmoudi et al. [102] investigated the link between physical-chemical prop- erties (size and surface charge) of SPIONs and PC composition. Specifically, they found that PC composition, in terms of relative amount and molecular weight of proteins, strongly depended on NPs size and surface charge. These factors are directly proportional, in other words, larger NPs preferentially adsorb proteins with a higher molecular weight, whereas proteins with a lower molecular weight accumulate on the surface of smaller NPs [102]. In addition, although surface charge plays an important role in the distribution and abundance of proteins that constitute the $\mathrm{PC}$, it is insignificant compared with the size of NPs. Hadjidemetriou et al. [66] confirmed the clear difference between the in vitro and in vivo PCs, and highlighted the need of studies designed to advance our understanding of the correlation between the physical-chemical characteristics of NPs and the nature of the incubation medium (in vitro vs in vivo, human or murine models).

The second consideration is that the new NP identity provided by the PC may result in the loss of targeting properties, thereby affecting the pharmacokinetics of a nanocarrier and its payload. This is the case, for example, of $3.5 \mathrm{~nm}$ sized, negatively charged SPIONs [102]. When incubated in vitro with $90 \%$ FBS, they adsorbed higher amounts of the small proteins ApoA-I and ApoA-II ( $\approx 30$ and $\approx 11 \mathrm{kDa}$, respectively) compared with positively charged and plain $3.5 \mathrm{~nm}$ SPIONs. As these apolipoproteins can cross the bloodbrain barrier through a saturable transport mechanism, once SPIONs were injected in vivo, ApoA-I and II were adsorbed on their surface and drove the NPs to brain vessels. This was demonstrated by magnetic resonance imaging only 5 min after injection. If not considered in advance, this behavior may result in neurotoxic sideeffects after injection of $3.5 \mathrm{~nm}$ SPIONs [102].

An understanding of the nano-bio interactions can be used to overcome the above reported limitations, for instance by modifying the NPs in a controlled manner to induce the binding of specific proteins. This concept is at the basis of the clever strategy recently developed by Prapainop et al. [101]. The judicious functionalization of the surface of quantum dots with 5,6-secosterol atheronal- $\mathrm{B}$ induced the binding to and misfolding of apolipoprotein B-100 (Apo-B100) in low-density lipoprotein (LDL) in the $\mathrm{PC}$. The conformational change induced by the misfolding of Apo-B100 causes the exposure of epitopes that bind cell-surface receptors on macrophage cells, which ultimately favors the selective uptake of atheronal-modified LDL particles by cells and foam cell formation [101]. Experimentally, the incubation of atheronal-functionalized particles with macrophages cultured in medium supplemented with fetal calf serum (which contains lipoproteins), lipoproteindeficient serum (LPDS) or delipidated LPDS, revealed 


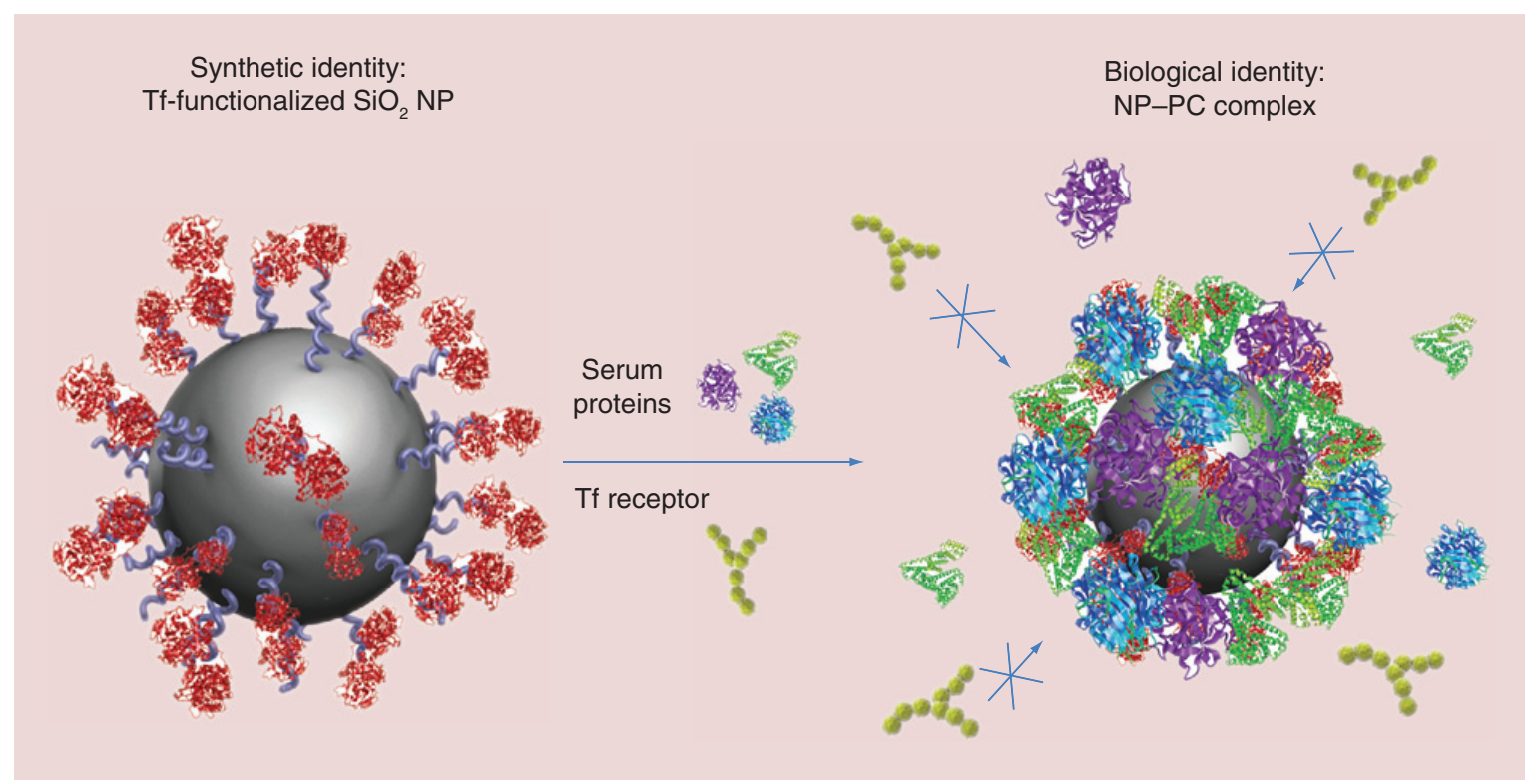

Figure 4. Negative impact of the protein corona on the nanoparticle-targeting ability. The PC hides the functionalization molecule (in this case, transferrin) on the NP surface, thereby inhibiting the interaction with its specific receptor on target cells.

NP: Nanoparticle; PC: Protein corona; Tf: Transferrin.

Adapted with permission from [103].

the presence of lipoproteins for cell uptake [101]. Other studies of the mechanisms of internalization revealed that CD36 is the key receptor on the macrophage surface that is responsible for interaction with atheronalmodified LDL particles [101]. This strategy could be used for the targeting of all $\mathrm{CD} 36^{+}$cells (e.g., adipocytes, skeletal muscle and retinal pigmental epithelial cells). In another study, PC formation was exploited to target cancer cells [107]. Briefly, the high affinity of vitronectin for the cationic-charged surface of lipoplexes was used to efficiently target the human breast cancer cells MDA-MB-435S, which overexpress two major vitronectin receptors. Internalization of naked lipoplexes (i.e., without a PC, and thus without vitronectin on their surface) was lower [107]. Figure 5 shows a schematic example in which the PC contributes to improve the NP targeting of a tumor cell.

\section{Toxicological implication of the PC}

The formation of a PC impacts not only on the targeting and delivery properties of NPs but it can also influence their toxicity and pathophysiology [36].

As for the NPs targeting, the chemical and physical characteristics of NPs and, eventually, the cellular phenotypes used in the study, play a relevant role in the potential toxic or nontoxic effects exerted by the PC. Moreover, even in the case of NPs with the same chemical and physical properties, it is difficult to compare the toxicological profile of the PC formed in different experimental conditions, because the relative quanti- ties of the adsorbed proteins can change remarkably. Lastly, the use of very different toxicity tests has jeopardized attempts to extrapolate general rules to define the biological impact of the PC on human cells, and it is still a significant obstacle to determine NPs toxicology [108-110]. In this scenario, there is a race to develop quantitative models to predict the biological identity that occurs after PC formation and eventually their cytotoxic properties. Our literature search indicates that, in terms of particle biocompatibility, the formation of a PC can be advantageous or disadvantageous in function of several factors [19]. In the next subsections we report information about both these cases in various NPs.

\section{When does the PC decrease nanoparticle toxicity?}

Many toxicity properties of NPs derive from the reactivity of their surface in interfacing cellular membrane. For example, positive charged NPs can perturb the continuity of plasma membrane, due to their interaction with the negatively charged surface of the cells [80]. This can lead to barrier disruption and, eventually, cell death [111]. The presence of a coating can mask these properties and can be considered a factor that increases the safety of NPs. This is true for both inorganic and biological coating. For example, the coating of zinc oxide $(\mathrm{ZnO})$ NPs with silica [112] or with a PC [113] was shown to decrease their toxicity toward human skin dermal fibroblasts and human hepatocarcinoma, 


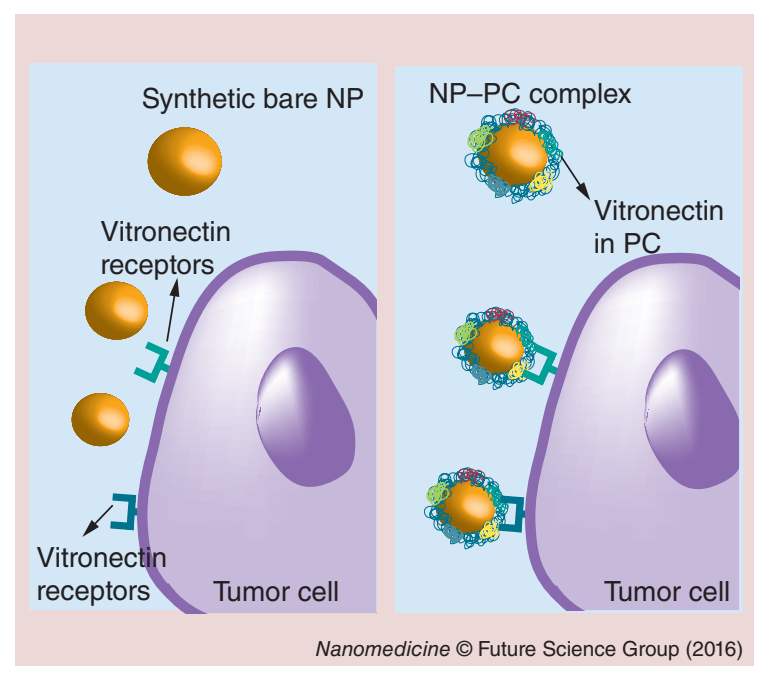

Figure 5. Positive impact of the protein corona on the nanoparticle-targeting ability. The PC contains proteins (in this case, vitronectin) that act as ligands for receptors on specific cells (tumor cells). This phenomenon, in theory, paves the way for induction of the PC formation to target selected cells. Elements not drawn to scale.

NP: Nanoparticle; PC: Protein corona.

respectively, by hampering direct surface contact between NPs and cells. Given their unique properties, carbon nanotubes (CNTs) have generated interest in a number of areas of medicine, including cancer therapy and diagnostics [114,115]. The toxicological implications related to their use have been widely discussed and are mainly due to the nonbiodegradable nature of these NPs [116,117]. However, even in this case, the binding of blood proteins to CNTs was shown to reduce their cytotoxic effect toward human acute monocytic leukemia (THP-1) and umbilical vein endothelial cells [29]. This is likely due to the effect of PC in protecting the cells from the direct contact with the bare surface of CNTs. Recently, the interaction between CNT-PC complexes and human blood platelets was also investigated [118]. De Paoli et al. demonstrated that the type of interaction between CNTs and platelets strongly depends on the identity of the proteins forming the PC [118]. Particularly, PCs made of different proteins may have opposite impacts: while albumin PCs decreased the platelets aggregation, histone $\mathrm{H} 1$ and gamma globulins PCs caused platelet aggregation and fragmentation, respectively [118].

The interaction between NPs and PC can also reduce systemic toxicity: Tenzer $e t$ al. [36] reported that freshly isolated human thrombocytes are activated by incubation with uncoated silica NPs. However, the same experiment performed with NP-PC complexes (obtained by incubating NPs in human plasma for 30 s) did not trigger this cell phenotype. Similarly, while uncoated silica NPs had a significant hemolytic effect on red blood cells, the formation of a PC on the particle surface protected the cells from this damage [36]. In this scenario, the innate surface charge of NPs is a crucial factor in determining NP toxicity in function of the PC. As mentioned above, the beneficial effect of the PC formation can be better appreciated when NPs are positively charged, as this physical feature possesses toxic properties [119]. Recently, the role of the PC in protecting cells from damage caused by positively charged NPs was elegantly demonstrated by the group of Dawson [119]. They showed that positively charged polystyrene NPs bearing a PC were trafficked with their coating to the lysosomes. In this cellular compartment, the PC was digested, thereby exposing the positive groups of the NPs that eventually exerted toxic effects on the cells by damaging lysosomal vesicles [119]. This is a general model that can be used to avoid deviations due to the chemical and physical properties of NPs in order to study the effective contribution of PC to NP toxicity.

In addition to protecting the cell membrane against reactive surfaces of NPs, the PC increases the safety of the carriers in other ways. For example, the protein coating that occurs in biological fluids can increase the stability of particles, which is important from the standpoint of cellular toxicity if the secondary degradation products of the carriers pose a potential threat.

This phenomenon was shown in $\mathrm{ZnO}$ [113] and silver (Ag) [120] NPs in which the formation of a PC inhibited NPs dissolution and consequent release of $\mathrm{Zn}$ and Ag ions that eventually became toxic for cells. Lastly, the formation of a PC can increase the safety of NPs by inhibiting the generation of radical oxygen species (ROS), by which several compounds exert their cytotoxic activity [121]. Nanoparticle toxicity can be related to the formation of ROS when the particles are composed of materials with semiconductor features [122,123]. In this context, $\mathrm{ZnO}$ NPs are again an example of this phenomenon because their pristine surface is a natural trigger of ROS, but the formation of a PC on their surface inhibits this phenomenon [113].

\section{When does the PC increase nanoparticle toxicity?}

The adsorption of proteins on the NP surface can induce protein denaturation by decreasing their thermal stability and favoring conformational changes of the adsorbed proteins. For example, titanium dioxide $\left(\mathrm{TiO}_{2}\right)$ NPs were shown to induce conformational changes of tubulin, thus inhibiting its polymerization properties [124], while gold NPs instead can induce changes in the conformation of serum albumin [125]. It was hypothesized that the cytotoxic mechanism 
underlying this phenomenon is the potential increased immunogenicity that the particles can exert by exposing protein epitopes on their surface in an aberrant conformation [34]. For example, it was demonstrated that the presence of poly(acrylic) acid on the surface of gold NPs induced unfolding of adsorbed fibrinogen that, in turn, interacted with the leukocyte receptor MAC-1, thereby triggering an inflammatory response [100]. The surface interaction of proteins at the nanoscale also affects protein fibrillation, which is at the base of neurodegenerative diseases such as Parkinson's and Alzheimer's [126]. This is an important observation, given to the role that was recognized to NPs in inhibiting the process of fibrillation and the consequent progress of the disease [127]. Recently, Mirsadeghi et al. found that the PC of gold NPs impacts the fibrillation process in a way that strongly depends on the protein source and concentration [128]. This is another demonstration of the need to review the data obtained without considering the presence of a PC, to better predict in vivo results.

Opinions differ as to whether or not the PC can affect cell internalization. However, the formation of a PC can increase internalization specificity, particularly in professional and non professional phagocytic cells such as macrophages and endothelial cells, causing an increase in the risk of cytoplasmic and systemic toxicity. Ag NPs were shown to be specifically internalized through scavenger receptors in endothelial cells, thereby activating intracellular pathways that increased the mRNA expression of the inflammatory cytokine IL-6 [129]. From this perspective, the elements of the innate immune system can exert a completely different action toward the presence of a PC and can lead to activation of the immune response.

Macrophages, considered the main players in the clearance of NPs from tissues, use phagocytosis to internalize NP-PC complexes, while naked NPs can be taken up through other mechanisms (i.e., clathrin- and dynamin-dependent endocytosis) [130]. In evaluating the inflammatory effects of NPs and their PC in monocyte cell lines in vitro, it is important to induce monocyte differentiation to a macrophage phenotype. Macrophages displayed a completely different profile of secreted inflammatory cytokines compared with undifferentiated monocytes when treated with PC-coated NPs [130]. Such leukocytes as macrophages, dendritic cells, eosinophils, neutrophils and mast cells express on their surface the Fc receptor, which binds with high-affinity opsonized material through the crystallizable fragment region of the antibodies. In some diseases in which the serum level of antibodies significantly increased, the use of NPs as therapeutic or diagnostic tools can be accompanied by the formation of a PC enriched in these molecules. As a result, the phagocytic process increases as do all the side-effects associated to NPs and their PCs related to the onset of inflammatory response [51]. This process is an excellent example of the complexity of the topic, and indicates that the formation of a PC can induce different toxicological responses in function of the specific cellular phenotype used in the study. A scheme of the pros and cons in terms of cytotoxicity is shown in Figure 6.

\section{Impact of the PC on the immune response}

The PC plays a role in cell uptake [131], accumulation, biodegradation and clearance of NPs [132]. It is becom-

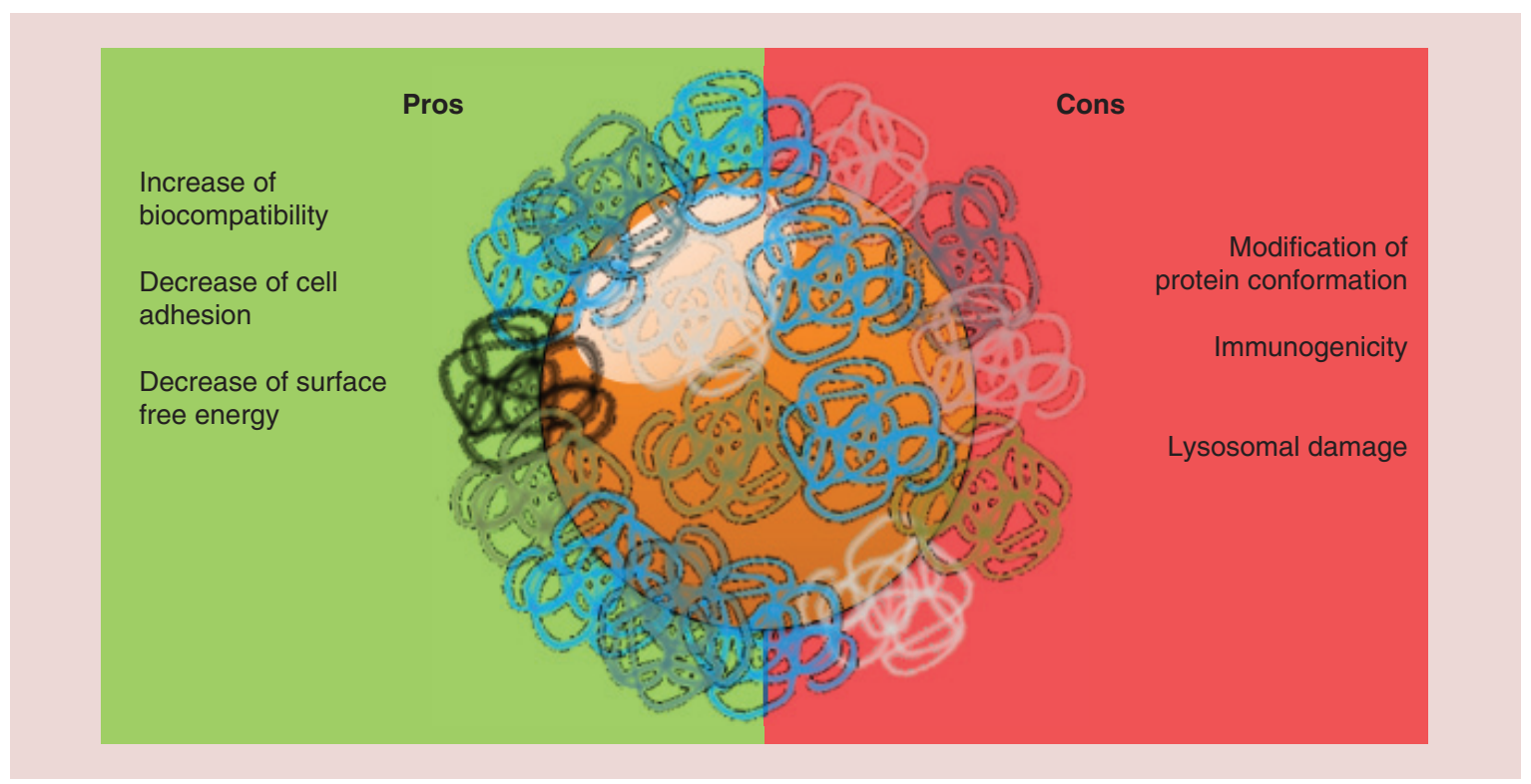

Figure 6. Impact of the protein corona on nanoparticle cytotoxicity. Schematic representation of the pros and cons of the protein corona in terms of cytotoxicity. 
ing clear that the PC also mediates and has the ability to alter the immune response. However, investigators are cautious and tend to refute the notion of differential immune stimuli dependence on the NP-PC. The immune system is expected to react to NPs and thus a better understanding of nano-immune interactions is critical for the safe application of engineered NPs in medicine [133]. In this section we discuss recent evidence that supports this meaningful mechanism. Specifically, we focus on the effect of the PC on the immune cell recognition of NPs, complement activation in response to NPs, the adaptive immune response and NP evasion of the reticulo-endothelial system.

The PC induces differential recognition of NPs by immune cells

The human body is equipped with mechanisms that protect the host against foreign entities. From a biological and physical point of view, injected NPs could be considered one of the potential body 'invaders' just like viruses or bacteria. Standing at the interface, the PC has a major impact on the interaction between immune cells and injected NPs. An example of this was provided by Yan et al. [134] who demonstrated the selective cell recognition for PC formation on poly-(methacrylic acid) nanoporous polymer particles. The levels of internalization of NPs in monocytes and macrophage-like cells differed significantly depending on the presence/absence of a PC (Figure 7). Compared to the uptake of bare NPs, NP uptake by monocytes (THP-1) was strongly inhibited by the presence of serum albumin. This phenomenon is most likely due to the conformational changes of the albumin once adsorbed on the NPs. On the contrary, in the case of macrophage-like cells (differentiated THP-1), the presence of albumin on the NP surface induced an increase in the internalization rate accompanied by secretion of inflammatory cytokines as proof of the activated phagocytosis $[134,135]$.

\section{Complement activation by NP-PC complexes}

The complement system identifies and induces the elimination process of nonself entities [136]. As expected, complement proteins were shown to be involved in the opsonization process and uptake of NPs [137,138]. While the complement can be activated through three pathways: classical, lectin, or alternative; NP-PC complexes seem to initiate the classical pathway [139].

Moreover, complement proteins that bind to NPs may lead to formation of a PC which implies activation of complement processes that eventually cause inflammation [140]. NPs may be designed to avoid such immune toxicity, and so improve their safety. In vitro experiments revealed that the physicochemical surface properties of NPs could mediate PC formation, and thus control the activation of complement pathways [141-143]. For example, it was shown that changing the surface chemical modification (e.g., methoxyl, carboxyl and amine groups) on polymeric NPs resulted in modulation of complement activation [141]. Another study demonstrated differential complement activation of gold NPs of different surface hydrophobicity by evaluating the complement protein $(\mathrm{C} 1)$ bound to IgG adsorbed on the nanosurface. The levels of complement activation were dramatically lower

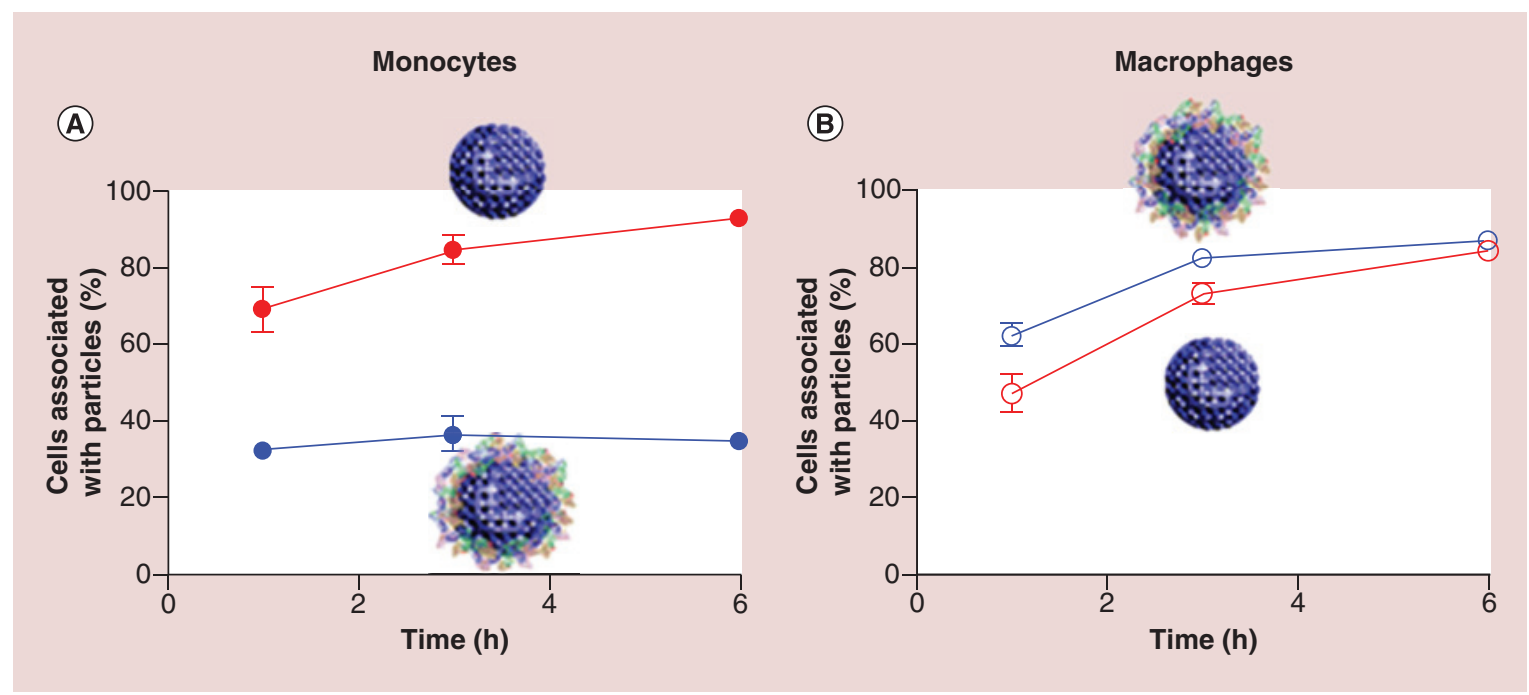

Figure 7. Mechanisms involved in nanoparticle-induced immunomodulation. The protein corona significantly affects nanoparticle-cell interactions (e.g., cell internalization and pathway activation). The different role of protein corona in nanoparticle uptake by monocytes and macrophages is represented.

Reproduced with permission from [134]. 
when the NP surface was hydrophilic than when it was hydrophobic [142]. Yu et al. instead used different conformational states of glycopolymer chains to induce the formation of a PC, which in turn, works as a 'molecular switch' of complement activation [143]. Taken together, these studies show that, because complement activation depends on surface modifications of the foreign body, it is possible to switch the complement cascade on/off through the modulation of the surface properties of NPs, among which, the PC plays a crucial role.

Adaptive immune response induction by NP-PC The adaptive immune system recognizes NPs because they are clearly 'nonself' and occasionally share biochemical properties with viruses (same biological properties and size range). NPs smaller than $10 \mathrm{~nm}$ may elude the immune system, although most remain dispersed at low concentrations. Elevated concentrations often result in particle aggregation and the consequent formation of macrostructures that can no longer be ignored by the immune system.

Moreover, NPs can be designed as adjuvants in order to manipulate the cytokine secretion profile, which will influence T-cell reactions [144]. An adaptive immune response usually occurs in a site that is already compromised, in which an innate immune reaction is ongoing. Such a response can enhance the existing inflammatory process occurring in the site. Adaptive immunity may be directed against the NP itself, even after formation of a PC, particularly if only a 'soft corona' has formed. Moreover, adaptive immunity may recognize nonself proteins, if these proteins have been introduced from outside the body (which is possible if the NPs are not sterile). However, cells of the immune system may never 'see' the naked NP surface, and the question is: do NPPC complexes present NP-associated molecular patterns to the immune system and induce its further activation? Rationally, the self-PC, when interacting with NPs, can stimulate the adaptive immune process if the complex created represents a 'danger' signal. Adsorbed proteins may undergo secondary and tertiary structure conformational changes, which ultimately lead to adaptive immune responses. The tertiary structure change from the NP-PC formation results in protein aggregation and induces the immunogenic potential of these self-proteins [145,146]. Candace et al. [72] characterized the changes in protein secondary structure that result from adsorption of serum albumin on NP surfaces. Such changes could initiate immune processes. For example, the PC has been reported to affect cell signaling involving cytokine production by activation of receptors, that in turn activate a signaling pathway (e.g., NF-kB), thus resulting in the secretion of inflammatory cytokines $[100,147]$.

\section{Evading the immune system}

In order to prolong NPs circulation time and avoid their early recognition from the immune system and the organs of the mononuclear phagocyte system (MPS), 'stealth' NPs were developed by coating them with the hydrophilic polymer PEG. This procedure creates a hydrodynamic radius around the surface of NPs, which is efficient in reducing the overall amount of serum adsorbed proteins, thus reducing macrophagedriven clearance, but does not affect their qualitative composition [148,149]. Furthermore, PEG plays a critical role in triggering inflammatory and immunogenic phenomena [51].

As for the active targeting approaches, the biomimicry concept was applied also for MPS escape. Various cellular membrane markers have been identified to confer immune surveillance properties to the cells. Among them, CD47, also known as integrin-associated protein, is widely expressed in human cells and serves as markerof-self on red blood [150]. Rodriguez et al., for example, inhibited macrophage uptake of their NPs by conjugating a 'stealth' self-peptide derived from human CD47 to the NP surface [151]. Using a different approach, Ashley et al. designed the 'protocells' by coating mesoporous silica NPs with a lipid bilayer that mimics the plasma membrane. This coating enabled the incorporation in the bilayer of molecules important for the celllike activity of these NPs (e.g., fusogenic peptides for the endosomal escape) [152]. Rather than using synthetic membranes, several groups recently began exploring strategies to obtain biological membranes from cells and using them to coat NP surface. We refer to these types of NPs (functionalized or made by cell membranes that provide them with cell-like functions) as 'bio-inspired NPs' [153,154] (Figure 8).

For example, red blood cell membranes have been used to coat NPs as well as to generate nanovesicles with liposome-like features in terms of drug loading and release capabilities [154,158]. Hu et al. demonstrated that red blood cell molecules were correctly transferred and oriented on the NPs surfaces [159]. Other bio-inspired NPs whose surface is functionalized through the integration of cell membranes, have been developed [153,156-157,160]. Among these, we used membrane proteins purified from leukocytes [161] to obtain the Leuko-like Vector (i.e., a nanopourous silica NP coated with leukocyte membranes). These vectors replicate white blood cell features showing a prolonged circulation time in the bloodstream and a natural tropism for the inflamed endothelium [156].

Using another biomimetic approach, Aimanianda et al. conjugated hydrophobin to the surface of porous silicon NPs. Hydrophobin is a surface protein that renders the spores of the human fungal pathogen Aspergillus fumigatus invisible to immune cells [162]. 


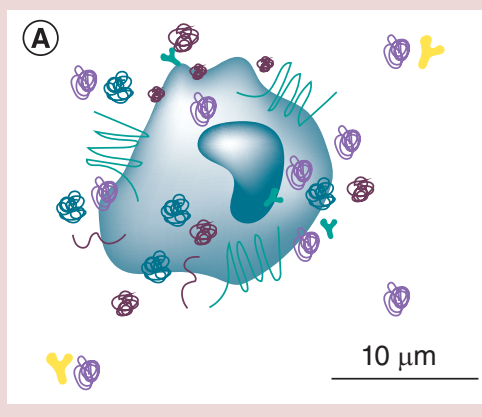

Specialized cell

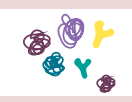

(B)
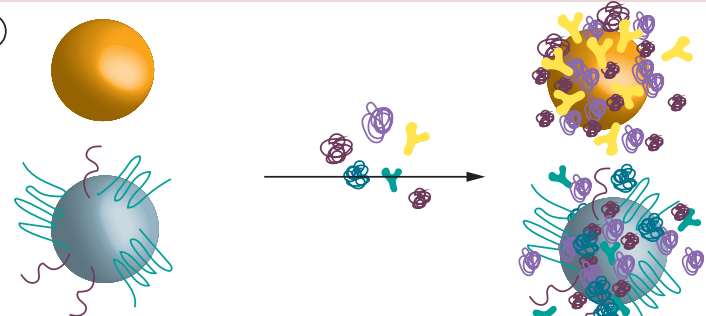

.

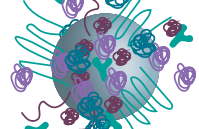

$100 \mathrm{~nm}$

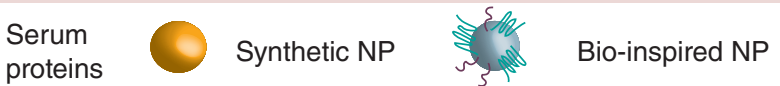

Nanomedicine @ Future Science Group (2016)

Figure 8. Protein corona of bio-inspired nanoparticles. The transfer of cellular membrane properties to synthetic NPs led to the development of the so-called biomimetic strategies. Specialized cell types (A), such as red blood cells [155], leukocytes [156] or platelets [157], inspired the development of particles that share a similar cellular membrane composition. The resulting vectors, defined as 'bio-inspired NPs', are recognized as self by the immune system. This could depend on the protein corona (PC) adsorbed on their surface. To date, no studies have been performed in order to describe the PC of bio-inspired NPs. (B) We hypothesize that while a synthetic NP is mainly recognized as nonself and adsorbs many serum proteins; bio-inspired NPs (reported to possess celllike capabilities [155-157]) absorb a specific PC similar to the PC of the cells used as membrane source for the NP synthesis. This confers self-like properties to the bio-inspired NPs and mediates their biological activity. NP: Nanoparticle.

The modified NPs displayed a significant change in the degree and composition of plasma protein adsorption in vitro. Moreover, when the bare NPs were injected intravenously, their accumulation was higher in spleen than in the liver (ratio of 2:1). However, hydrophobin coating changed the ratio of NP uptake by the MPS organs and resulted in an opposite trend of accumulation [163].

Again, the aforementioned examples underline how the chemical modifications of NPs surface affect their biological fate. As the PC represents the new biointerface between NPs and biological fluids, then it is of great importance the understanding of the key players that regulate particle recognition and their mechanisms. While there are several studies about the PC-mediated clearance of conventional NPs, to the best of our knowledge, there are no studies related to the PC of such type of bio-inspired NPs.

If the biomimetic coating improved the biological performances of such NPs, one could speculate that the PC actively mediates the recognition of surface markers and, eventually, 'communicates' their presence as 'self' to the cells responsible for 'nonself' clearance.

In Figure 8, we illustrate a potential mechanism that governs the PC formation for bio-inspired NPs. Synthetic NPs react with serum proteins according to the mechanisms described in this article. Bio-inspired NPs attract serum proteins according to their physicochemical properties (as synthetic NPs). On the other hand, they further discriminate among the serum proteins depending on the affinity of the latter to the biomimetic coating. The result is that bio-inspired NPs may absorb a PC similar to the one that the original cells present. This confers selflike properties to bio-inspired NPs, thus mediating their biological activity. Therefore, it is evident how further studies on the interaction between bio-inspired NPs surface and serum proteins are necessary in order to better understand the potentiality of the biomimicry strategies associated with the nanotechnology field. In addition, it will provide insights to the molecular mechanisms of PC formation and its biological relevance.

\section{Conclusion}

To reach its target, synthetic NPs enter into contact with a biological environment that confers them a bio-identity (i.e., the PC). During recent years there has been a remarkable increase in the number of studies about the PC (Figure 9). New concepts have emerged in nanotechnology and, as a consequence, the complexity of NP features needs to be addressed in an experimental set up characterized by new steps (Figure 1). Since the PC is the 'effective' particle surface, it interacts with cells and tissues thus affecting the function of NPs, namely targeting, toxicity and escape from the immune response. However, its specific role is still under debate, and discordant results have been reported and discussed in this article. How can these controversial results be explained and is there any way to predict the fate of a NP in vivo based on its surface chemistry and, in vitro properties? 
These questions should be addressed based on three considerations. First, we should determine how the physicochemical properties of NPs (i.e., surface charge and, in particular, their size) differ from each other and affect the type of proteins that will be adsorbed on carrier surface once NPs are immersed into biological fluids. Tailoring these two parameters, for example, can help to include/exclude a class of proteins with respect to another one. Second, in the case of targeted NPs, we should consider that the targeting agents differ from each other in terms of molecular weight, size and charge. They also differ in affinity with their ligand on the target cell surface and in their density on the carrier surface [106]. In comparison to a small molecule (e.g., transferrin), an antibody may be not easily shielded by the PC, thus preserving the targeting ability of the functionalized NPs. Lastly, diverse biological factors, for example, serum concentration, in vitro or in vivo conditions, as well as murine or human serum, affect the PC composition, thereby altering the biological identity that the particles acquire and, consequently, their biological fate.

\section{Future perspective}

We can affirm that the PC concept is almost completely accepted, even if it is too early to claim that we have a clear understanding of its role in nanomedicine. Therefore, the scientific community is starting to reconsider the previously obtained data on NPs features and effects, in the light of the existence of a PC. The following items should be considered for the future studies: i) Continue characterizing PCs, taking into account that the $\mathrm{PC}$ is characterized by strong and weak interactions and we still need to understand the role of the latter. In fact, the experimental needs have given a greater space to the studies on the hard corona, but we should start to consider the idea of focusing more attention also on the other side of the coin: the soft corona. ii) Understand how to modulate the formation of the PC.This can be done either by trying to inhibit the formation of a PC through NP surface modification or by taking advantage of the formation of a PC to obtain specific NP properties. The ability to tune the formation of a PC represents an additional value in the design of novel drug delivery platforms. It may open the way to new possibilities in nanomedicine, such as decreasing toxicity and/or improving of cellular uptake and the potential driving of the targeting. More investigations are needed to better understand how the 'real' corona directs the NPs in the body. The intensification of studies that better reproduce the in vivo conditions is now crucial. Knowledge of the NP-PC interaction with blood components and the target site would allow bio-engineers to better design the next generation of drug delivery systems. Furthermore, it has been recently demonstrated that the PC composition strongly changes, if plasma deriving from the blood of patients with different diseases is employed for the incubation of NPs [44,50]. Thus, the new concept of 'personalized protein corona' has been introduced. We believe that, in the next not too distant future, we may expect to see the engineering of patient-specific NPs in a disease type-specific manner for safer clinical applications. Lastly, as discussed above, the lack of information about the PC of bio-inspired NPs is an important challenge that has to still be resolved. The knowledge of the PC of these NPs, synthesized using membranes (lipids and proteins) extracted from live cells (e.g., leukocytes and red blood cells), is fascinating as it could help to better understand the potentiality of the biomimicry strategies in nanomedicine.

\section{Summary}

When immersed in biological fluids, the high surface free energy of NPs promotes the absorption of biomolecules thereby forming the PC. The formation of a PC causes changes in the charge, size and surface chemistry of a given NP, thereby impacting on its uptake and cellular fate. An understanding of the interaction between NPs and biological fluids is a prerequisite for the control of this phenomenon and for engineered development of NPs that have a favorable biodistribution and biocompatibility. The composition of the surface protein layer consists mainly of negatively charged proteins, with a molecular weight typically higher than $60 \mathrm{kDa}$. A subset of about 125 proteins involved in complement activation, pathogen recog-

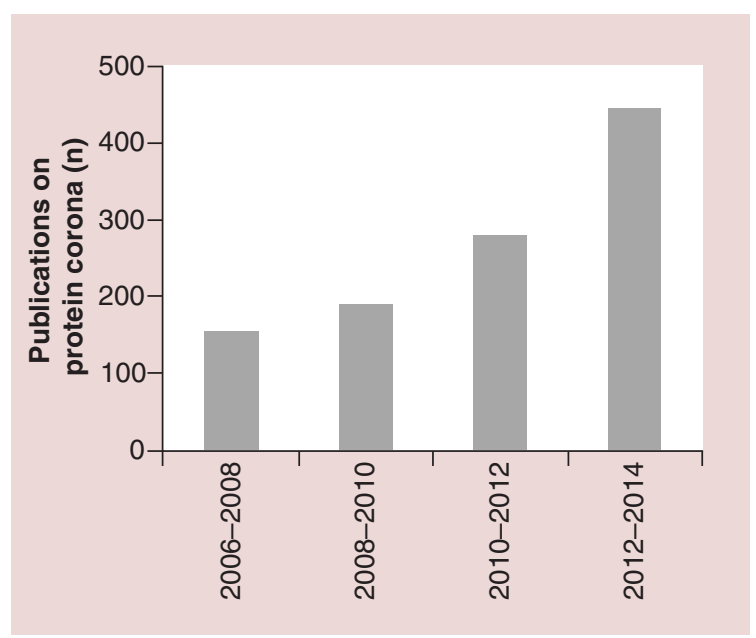

Figure 9. Number of articles devoted to the protein corona published from 2006 to 2014. The number of articles has tripled during the 3 years between 2012-2014 versus 2006-2008. 
nition and blood coagulation is commonly adsorbed on nanomaterials. This review is devoted to recent acquisitions regarding the role of the PC in NP functions and in the development of new strategies with which to modulate the PC to more efficiently target specific cells. The impact of the PC on NPs properties is discussed.

\section{Acknowledgements}

The authors thank Associazione Bianca Garavaglia, Via C. Cattaneo, 8, 21052 Busto Arsizio Varese, Italy. The authors thank
Jean Ann Gilder (Scientific Communication spa, Naples, Italy) and Kelly A Hartman for editing the text and Federico Urzi for graphical assistance. The authors are grateful to the reviewers for their comments and observations that helped to improve this manuscript.

Financial \& competing interests disclosure

This work was supported by grants RF-2010-2318372 and RF-2010-2305526 from Italian Ministry of Health, and by grants 1R21CA173579-01A1 from NIH/NCI, 5U54CA143837 PSOC Pilot project from NIH/NCl, W81XWH-12-10414 BCRP

\section{Executive summary}

\section{Background}

- Once injected in a physiological environment, nanoparticles (NPs) interact with biological components and are surrounded by a protein corona (PC).

- The PC can trigger an immune response and affect NP toxicity and targeting capabilities.

Dynamics of PC formation

- Time evolution studies on the composition of the PC have demonstrated for long time that the process of NP-PC complex formation follows the Vroman effect.

- According to the Vroman effect, an initially attached protein can, at any time, desorb from a NP and be replaced by a different one with major affinity. The PC is a highly dynamic over time. Its composition changes, while the amount of adsorbed proteins remains relatively constant.

- Instead, recent findings show that the PC is already established $0.5 \mathrm{~min}$ after injection. Its composition remains constant over time, while the amount of adsorbed proteins changes.

PC composition

- The PC is not universal, but is unique for each type of NP.

- The proteins generally identified in the PC are involved in complement activation, blood coagulation and foreign body recognition processes.

- Albumin, apolipoproteins, IgG and fibrinogen, are present in the PC of almost all NPs investigated.

- Proteomic-based approaches are widely used for the characterization of the PC. Among these, label-free MS has several benefits that include a low number of steps in the protocol and high reproducibility.

- The majority of the in vitro studies seems to be only partially relevant from a biological point of view because the incubation of NPs inadequately replicates the conditions of an intact biological system.

- Few attempts of in vivo experiments are now emerging.

Impact of the PC on the targeting capability of NPs

- The impact of the PC on the targeting capabilities of NPs is still under debate.

- It has been shown that the PC can have a dual role: in some cases, it hides the functionalization molecule on the NP surface, thereby inhibiting the interaction with its specific receptor on the target cells; in other cases, the PC contains proteins that act as ligands for receptors on specific cells.

- NP synthesis can be manipulated to favor the binding of specific proteins in the PC in order to target selected cells.

Toxicological implication of the PC

- Results about the toxicological implication of the PC are discordant.

- It has been demonstrated that the PC is cytotoxic (because it induces conformational changes of the proteins, or causes the NPs to aggregate).

- Unfolded or misfolded proteins lose their functional activity and are associated to various diseases.

- On the other hand the PC may increase the biocompatibility of NPs, especially in the interaction with cell membranes.

How does the NP-PC complex affect the immune response?

- The immune system does not see a 'naked' NP, thanks also to the PC.

- What role does the PC play in the immune system-NP interaction? What impact does the PC have on the immune response when it recognizes an NP? We address these questions by examining the different compartments of the immune system.

- The PC induces differential recognition of NP by immune cells. In addition, the response developed by either innate or adaptive immunity is PC dependent. Finally we discussed how the PC helps NPs evade the immune system. 
Innovator Expansion from Department of Defence and The Regenerative Medicine Program Cullen Trust for Health Care to E Tasciotti and by POR Campania FSE 2007-2013 Project DIAINTECH, Italy (to F Salvatore). The authors have no other relevant affiliations or financial involvement with any

\section{References}

Papers of special note have been highlighted as: $\bullet$ of interest

1 Maiorano G, Sabella S, Sorce B et al. Effects of cell culture media on the dynamic formation of protein- nanoparticle complexes and influence on the cellular response. ACS Nano 4(12), 7481-7491 (2010).

2 Walkey CD, Chan WC. Understanding and controlling the interaction of nanomaterials with proteins in a physiological environment. Chem. Soc. Rev. 41(7), 2780-2799 (2012).

3 Cedervall T, Lynch I, Lindman S et al. Understanding the nanoparticle-protein corona using methods to quantify exchange rates and affinities of proteins for nanoparticles. Proc. Natl Acad. Sci. USA 104(7), 2050-2055 (2007).

- Introduces the concept of the nanoparticle-protein corona and provides evidence of the biomolecular exchange timescale that revealed the dynamic nature of the protein corona.

4 Wan S, Kelly PM, Mahon E et al. The "sweet" side of the protein corona: effects of glycosylation on nanoparticle-cell interactions. ACS Nano 9(2), 2157-2166 (2015).

5 Hellstrand E, Lynch I, Andersson A et al. Complete highdensity lipoproteins in nanoparticle corona. FEBS J. 276(12), 3372-3381 (2009).

6 Diederichs JE. Plasma protein adsorption patterns on liposomes: establishment of analytical procedure. Electrophoresis 17(3), 607-611 (1996).

7 Lück M, Paulke BR, Schröder W, Blunk T, Müller R. Analysis of plasma protein adsorption on polymeric nanoparticles with different surface characteristics. J. Biomed. Mater. Res. 39(3), 478-485 (1998).

8 Gessner A, Waicz R, Lieske A, Paulke B-R, Mäder K, Müller R. Nanoparticles with decreasing surface hydrophobicities: influence on plasma protein adsorption. Int. J. Pharm. 196(2), 245-249 (2000).

9 Monopoli MP, Åberg C, Salvati A, Dawson KA. Biomolecular coronas provide the biological identity of nanosized materials. Nat. Nanotechnol. 7(12), 779-786 (2012).

10 Lundqvist M. Nanoparticles: tracking protein corona over time. Nat. Nanotechnol. 8(10), 701-702 (2013).

11 Milani S, Baldelli Bombelli F, Pitek AS, Dawson KA, RäDler J. Reversible versus irreversible binding of transferrin to polystyrene nanoparticles: soft and hard corona. ACS Nano 6(3), 2532-2541 (2012).

12 Dell'orco D, Lundqvist M, Oslakovic C, Cedervall T, Linse $S$. Modeling the time evolution of the nanoparticle-protein corona in a body fluid. PLoS ONE 5(6), e10949 (2010).

13 Hosseini M, Jiang L, Sorensen HP et al. Elucidation of the contribution of active site and exosite interactions to affinity and specificity of peptidylic serine protease inhibitors using non-natural arginine analogs. Mol. Pharmacol. 80 (4), 585-597 (2011). organization or entity with a financial interest in or financial conflict with the subject matter or materials discussed in the manuscript apart from those disclosed.

No writing assistance was utilized in the production of this manuscript.

14 Lesniak A, Fenaroli F, Monopoli MP, Åberg C, Dawson KA, Salvati A. Effects of the presence or absence of a protein corona on silica nanoparticle uptake and impact on cells. ACS Nano 6(7), 5845-5857 (2012).

15 Jiang X, Weise S, Hafner M et al. Quantitative analysis of the protein corona on FePt nanoparticles formed by transferrin binding. J. R. Soc. Interface 7(Suppl. 1), S5-S13 (2010).

16 Safi M, Courtois J, Seigneuret M, Conjeaud H, Berret $\mathrm{J}$-F. The effects of aggregation and protein corona on the cellular internalization of iron oxide nanoparticles. Biomaterials 32(35), 9353-9363 (2011).

17 Casals E, Pfaller T, Duschl A, Oostingh GJ, Puntes VF. Hardening of the nanoparticle-protein corona in metal $(\mathrm{Au}, \mathrm{Ag})$ and oxide $\left(\mathrm{Fe}_{3} \mathrm{O}_{4}, \mathrm{CoO}\right.$, and $\left.\mathrm{CeO}_{2}\right)$ nanoparticles. Small 7(24), 3479-3486 (2011).

18 Kah JCY, Chen J, Zubieta A, Hamad-Schifferli K. Exploiting the protein corona around gold nanorods for loading and triggered release. ACS Nano 6(8), 6730-6740 (2012).

19 Walkey CD, Olsen JB, Song F et al. Protein corona fingerprinting predicts the cellular interaction of gold and silver nanoparticles. ACS Nano 8(3), 2439-2455 (2014).

20 Caracciolo G, Callipo L, De Sanctis SC, Cavaliere C, Pozzi $\mathrm{D}$, Laganà A. Surface adsorption of protein corona controls the cell internalization mechanism of DC-Chol-DOPE/ DNA lipoplexes in serum. Biochim. Biophys. Acta 1798(3), 536-543 (2010).

21 Caracciolo G, Pozzi D, Capriotti AL et al. Evolution of the protein corona of lipid gene vectors as a function of plasma concentration. Langmuir 27(24), 15048-15053 (2011).

22 Pozzi D, Colapicchioni VG et al. Effect of polyethyleneglycol (PEG) chain length on the bio-nano-interactions between PEGylated lipid nanoparticles and biological fluids: from nanostructure to uptake in cancer cells. Nanoscale 6(5), 2782-2792 (2014).

23 Dos Santos N, Allen C, Doppen A-M et al. Influence of poly (ethylene glycol) grafting density and polymer length on liposomes: relating plasma circulation lifetimes to protein binding. Biochim. Biophys. Acta 1768(6), 1367-1377 (2007).

24 Monopoli MP, Walczyk D, Campbell A et al. Physicalchemical aspects of protein corona: relevance to in vitro and in vivo biological impacts of nanoparticles. J. Am. Chem. Soc. 133(8), 2525-2534 (2011).

25 Anderson NL, Polanski M, Pieper R et al. The human plasma proteome. Mol. Cell. Proteomics 3(4), 311-326 (2004).

26 Zhang H, Burnum KE, Luna ML et al. Quantitative proteomics analysis of adsorbed plasma proteins classifies nanoparticles with different surface properties and size. Proteomics 11(23), 4569-4577 (2011).

27 Dobrovolskaia MA, Patri AK, Zheng J et al. Interaction of colloidal gold nanoparticles with human blood: effects on 
particle size and analysis of plasma protein binding profiles. Nanomed. Nanotechnol. Biol. Med. 5(2), 106-117 (2009).

28 Tenzer S, Docter D, Rosfa $\mathrm{S}$ et al. Nanoparticle size is a critical physicochemical determinant of the human blood plasma corona: a comprehensive quantitative proteomic analysis. ACS Nano 5(9), 7155-7167 (2011).

29 Ge C, Du J, Zhao L et al. Binding of blood proteins to carbon nanotubes reduces cytotoxicity. Proc. Natl Acad. Sci. USA 108(41), 16968-16973 (2011).

30 Martel J, Young D, Young A et al. Comprehensive proteomic analysis of mineral nanoparticles derived from human body fluids and analyzed by liquid chromatography-tandem mass spectrometry. Anal. Biochem. 418(1), 111-125 (2011).

- One of the first studies reporting data about protein corona composition in human body fluids other than blood plasma.

31 Casals E, Pfaller T, Duschl A, Oostingh GJ, Puntes V. Time evolution of the nanoparticle protein corona. ACS Nano 4(7), 3623-3632 (2010).

- One of the early studies about the kinetics of the hard corona.

32 Vroman L, Adams AL. Identification of rapid changes at plasma-solid interfaces. J. Biomed. Mater. Res. 3(1), 43-67 (1969).

33 Vroman L. Effect of adsorbed proteins on the wettability of hydrophilic and hydrophobic solids. Nature 196, 476-477 (1962).

34 Nel AE, Mädler L, Velegol D et al. Understanding biophysicochemical interactions at the nano-bio interface. Nat. Mater. 8(7), 543-557 (2009).

35 Cedervall T, Lynch I, Foy M et al. Detailed identification of plasma proteins adsorbed on copolymer nanoparticles. Angew. Chem. Int. Ed. Engl. 46(30), 5754-5756 (2007).

36 Tenzer S, Docter D, Kuharev J et al. Rapid formation of plasma protein corona critically affects nanoparticle pathophysiology. Nat. Nanotechnol. 8(10), 772-781 (2013).

37 Docter D, Westmeier D, Markiewicz M, Stolte S, Knauer S, Stauber R. The nanoparticle biomolecule corona: lessons learned-challenge accepted? Chem. Soc. Rev. 44(17), 6094-6121 (2015).

- Elegant comprehensive review of the recent findings on the topic. The authors also discuss the ecological impact of the nanoparticle-protein corona complex on the aquatic and terrestrial environments.

38 Lundqvist M, Stigler J, Elia G, Lynch I, Cedervall T, Dawson KA. Nanoparticle size and surface properties determine the protein corona with possible implications for biological impacts. Proc. Natl Acad. Sci. USA 105(38), 14265-14270 (2008).

39 Deng ZJ, Mortimer G, Schiller T, Musumeci A, Martin D, Minchin RF. Differential plasma protein binding to metal oxide nanoparticles. Nanotechnology 20 (45), 455101 (2009).

40 Qiu Y, Liu Y, Wang L et al. Surface chemistry and aspect ratio mediated cellular uptake of Au nanorods. Biomaterials 31(30), 7606-7619 (2010).

41 Capriotti AL, , G, Cavaliere C et al. Do plasma proteins distinguish between liposomes of varying charge density? J. Proteomics 75(6), 1924-1932 (2012).

42 Pozzi D, , G, Capriotti AL et al. Surface chemistry and serum type both determine the nanoparticle-protein corona. J. Proteomics 119, 209-217 (2015).

43 Mahmoudi M, Abdelmonem AM, Behzadi S et al. Temperature: the "ignored" factor at the nanobio interface. ACS Nano 7(8), 6555-6562 (2013).

44 Hajipour MJ, Laurent S, Aghaie A, Rezaee F, Mahmoudi M. Personalized protein coronas: a "key" factor at the nanobiointerface. Biomater. Sci. 2(9), 1210-1221 (2014).

45 Foroozandeh P, Aziz AA. Merging worlds of nanomaterials and biological environment: factors governing protein corona formation on nanoparticles and its biological consequences. Nanoscale Res. Lett. 10(1), 1-12 (2015).

46 Aggarwal P, Hall JB, Mcleland CB, Dobrovolskaia MA, Mcneil SE. Nanoparticle interaction with plasma proteins as it relates to particle biodistribution, biocompatibility and therapeutic efficacy. Adv. Drug Del. Rev. 61(6), 428-437 (2009).

47 Webster TJ. Interview: Nanomedicine: past, present and future. Nanomedicine 8(4), 525-529 (2013).

48 Landgraf L, Christner C, Storck W et al. A plasma protein corona enhances the biocompatibility of $\mathrm{Au}_{0} \mathrm{Fe}_{3} \mathrm{O}_{4}$ Janus particles. Biomaterials 68, 77-88 (2015).

49 Sobczynski DJ, Charoenphol P, Heslinga MJ et al. Plasma protein corona modulates the vascular wall interaction of drug carriers in a material and donor specific manner. PLoS ONE 9(9), e107408 (2014).

50 Hajipour MJ, Raheb J, Akhavan O et al. Personalized diseasespecific protein corona influences the therapeutic impact of graphene oxide. Nanoscale 7(19), 8978-8994 (2015).

51 Wolfram J, Yang Y, Shen J et al. The nano-plasma interface: implications of the protein corona. Colloids Surf. B Biointerfaces 124, 17-24 (2014).

52 Docter D, Strieth S, Westmeier D et al. No king without a crown-impact of the nanomaterial-protein corona on nanobiomedicine. Nanomedicine 10(3), 503-519 (2015).

53 Choi HS, Ashitate Y, Lee JH et al. Rapid translocation of nanoparticles from the lung airspaces to the body. Nat. Biotechnol. 28(12), 1300-1303 (2010).

54 Kumar A, Forbes B, Mudway I, Bicer EM, Dailey LA. What are the biological and therapeutic implications of biomolecule corona formation on the surface of inhaled nanomedicines? Nanomedicine (Lond.) 10(3), 343 (2015).

55 Ruge CA, Schaefer UF, Herrmann J et al. The interplay of lung surfactant proteins and lipids assimilates the macrophage clearance of nanoparticles. PLoS ONE 7(7), e40775 (2012).

56 Ruge CA, Kirch J, Cañadas O et al. Uptake of nanoparticles by alveolar macrophages is triggered by surfactant protein A Nanomed. Nanotechnol. Biol. Med. 7(6), 690-693 (2011).

57 Schulze C, Schaefer UF, Ruge CA, Wohlleben W, Lehr C-M. Interaction of metal oxide nanoparticles with lung surfactant protein A. Eur. J. Pharm. Biopharm. 77(3), 376-383 (2011).

58 Lee J-A, Kim M-K, Kim H-M et al. The fate of calcium carbonate nanoparticles administered by oral route: 
absorption and their interaction with biological matrices. Int. J. Nanomedicine 10, 2273 (2015).

59 Sund J, Alenius H, Vippola M, Savolainen K, Puustinen A. Proteomic characterization of engineered nanomaterialprotein interactions in relation to surface reactivity. ACS Nano 5(6), 4300-4309 (2011).

60 Capriotti AL, Caruso G et al. Analysis of plasma protein adsorption onto DC-Chol-DOPE cationic liposomes by HPLC-CHIP coupled to a Q-TOF mass spectrometer. Anal. Bioanal. Chem. 398(7-8), 2895-2903 (2010).

61 Gossmann R, Fahrländer E, Hummel M, Mulac D, Brockmeyer J, Langer K. Comparative examination of adsorption of serum proteins on HSA-and PLGA-based nanoparticles using SDS-PAGE and LC-MS. Eur. J. Pharm. Biopharm. 93, 80-87 (2015).

62 Sakulkhu U, Maurizi L, Mahmoudi M et al. Ex situ evaluation of the composition of protein corona of intravenously injected superparamagnetic nanoparticles in rats. Nanoscale 6(19), 11439-11450 (2014).

63 Sakulkhu U, Mahmoudi M, Maurizi L, Salaklang J, Hofmann $\mathrm{H}$. Protein corona composition of superparamagnetic iron oxide nanoparticles with various physico-chemical properties and coatings. Sci. Rep. 4, 5020 (2014).

64 Capriotti AL, Caruso G et al. Label-free quantitative analysis for studying the interactions between nanoparticles and plasma proteins. Anal. Bioanal. Chem. 405(2-3), 635-645 (2013).

65 Johnstone SA, Masin D, Mayer L, Bally MB. Surfaceassociated serum proteins inhibit the uptake of phosphatidylserine and poly (ethylene glycol) liposomes by mouse macrophages. Biochim. Biophys. Acta 1513(1), 25-37 (2001).

66 Hadjidemetriou M, Al-Ahmady Z, Mazza M, Collins RF, Dawson K, Kostarelos K. In vivo biomolecule corona around blood-circulating, clinically used and antibody-targeted lipid bilayer nanoscale vesicles. ACS Nano 9(8), 8142-8156 (2015).

- The authors compare the protein corona of Doxil (a clinically used liposome-based formulation) after in vivo injection and after in vitro incubation. Their results highlight the large gap between in vitro studies and physiological systems.

67 Salvatore F, Corbo C, Gemei M, Del Vecchio L. Oncoproteomic approaches to cancer marker discovery: the case of colorectal cancer. Biomark. Cancer 53-71 (2015).

68 Webb-Robertson B-JM, Wiberg HK, Matzke MM et al. Review, evaluation, and discussion of the challenges of missing value imputation for mass spectrometry-based labelfree global proteomics. J. Proteome Res. 14(5), 1993-2001 (2015).

69 Shannahan JH, Lai X, Ke PC, Podila R, Brown JM, Witzmann FA. Silver nanoparticle protein corona composition in cell culture media. PLoS ONE 8(9), e74001 (2013).

70 Shannahan JH, Brown JM, Chen R et al. Comparison of nanotube-protein corona composition in cell culture media. Small 9(12), 2171-2181 (2013).
71 Ritz S, SchöTtler S, Kotman N et al. Protein corona of nanoparticles: distinct proteins regulate the cellular uptake. Biomacromolecules 16(4), 1311-1321 (2015).

72 Fleischer CC, Payne CK. Secondary structure of corona proteins determines the cell surface receptors used by nanoparticles. J. Phys. Chem. B 118(49), 14017-14026 (2014).

73 Sánchez-Moreno P, Buzón P, Boulaiz $\mathrm{H}$ et al. Balancing the effect of corona on therapeutic efficacy and macrophage uptake of lipid nanocapsules. Biomaterials 61, 266-278 (2015).

74 Longo D, Fauci A, Kasper D, Hauser S. Harrison's Principles of Internal Medicine (18th Edition). McGraw-Hill Professional, NY, USA (2011).

75 Caracciolo G, Pozzi D, Capriotti AL et al. The liposomeprotein corona in mice and humans and its implications for in vivo delivery. J. Mater. Chem. B 2(42), 7419-7428 (2014).

- The authors demonstrate that liposome incubation in human and mouse plasma results in different protein coronas. This is an important observation for the targeted capability of nanoparticles that shows the potential limitations of extrapolating data from mouse to human.

76 Kirui DK, Celia C, Molinaro R et al. Mild hyperthermia enhances transport of liposomal gemcitabine and improves in vivo therapeutic response. Adv. Healthc. Mater. 4(7), 1092-1103 (2015).

77 Cosco D, Federico C, Maiuolo J et al. Physicochemical features and transfection properties of chitosan/poloxamer 188/poly (D, L-lactide-co-glycolide) nanoplexes. Int. J. Nanomedicine 9, 2359 (2014).

78 Martinez JO, Evangelopoulos M, Karun V et al. The effect of multistage nanovector targeting of VEGFR2 positive tumor endothelia on cell adhesion and local payload accumulation. Biomaterials 35(37), 9824-9832 (2014).

79 Yang T, Cui F-D, Choi M-K et al. Enhanced solubility and stability of PEGylated liposomal paclitaxel: in vitro and in vivo evaluation. Int. J. Pharm. 338(1), 317-326 (2007).

80 Molinaro R, Wolfram J, Federico C et al. Polyethylenimine and chitosan carriers for the delivery of RNA interference effectors. Expert Opin. Drug Deliv. 10 (12), 1653-1668 (2013).

81 Ferrari M. Cancer nanotechnology: opportunities and challenges. Nat. Rev. Cancer 5(3), 161-171 (2005).

82 Bertrand N, Wu J, Xu X, Kamaly N, Farokhzad OC. Cancer nanotechnology: the impact of passive and active targeting in the era of modern cancer biology. Adv. Drug Deliv. Rev. 66, 2-25 (2014).

83 Parhi P, Mohanty C, Sahoo SK. Nanotechnology-based combinational drug delivery: an emerging approach for cancer therapy. Drug Discov. Today 17(17), 1044-1052 (2012).

84 Dobrovolskaia MA, Mcneil SE. Strategy for selecting nanotechnology carriers to overcome immunological and hematological toxicities challenging clinical translation of nucleic acid-based therapeutics. Expert Opin. Drug Deliv. (0), $1-13$ (2015).

85 Gu FX, Karnik R, Wang AZ et al. Targeted nanoparticles for cancer therapy. Nano Today 2(3), 14-21 (2007). 
86 Torchilin VP. Multifunctional, stimuli-sensitive nanoparticulate systems for drug delivery. Nat. Rev. Drug Discov. 13(11), 813-827 (2014).

87 Koren E, Apte A, Jani A, Torchilin VP. Multifunctional PEGylated 2C5-immunoliposomes containing $\mathrm{pH}$ sensitive bonds and TAT peptide for enhanced tumor cell internalization and cytotoxicity. J. Control. Release 160(2), 264-273 (2012).

88 Tope S, Maske S, Nagulwar V, Sufi J, Welankiwar A. Aptamers as therapeutics. Indo Am. J. Pharm. Res. 3(3), 2718-2743 (2013).

89 Danhier F, Feron O, Préat V. To exploit the tumor microenvironment: passive and active tumor targeting of nanocarriers for anti-cancer drug delivery. J. Control. Release 148(2), 135-146 (2010).

90 Allen TM, Cullis PR. Liposomal drug delivery systems: from concept to clinical applications. Adv. Drug Del. Rev. 65(1), 36-48 (2013).

91 Choi CHJ, Alabi CA, Webster P, Davis ME. Mechanism of active targeting in solid tumors with transferrin-containing gold nanoparticles. Proc. Natl Acad. Sci. USA 107(3), 1235-1240 (2010).

92 Blanco E, Shen H, Ferrari M. Principles of nanoparticle design for overcoming biological barriers to drug delivery. Nat. Biotechnol. 33(9), 941-951 (2015).

93 Parodi A, Corbo C, Cevenini A et al. Enabling cytoplasmic delivery and organelle targeting by surface modification of nanocarriers. Nanomedicine 10(12), 1923-1940 (2015).

94 Ferrari M, Onuoha SC, Pitzalis C. Trojan horses and guided missiles: targeted therapies in the war on arthritis. Nat. Rev. Rheumatol. 11(6), 328-337 (2015).

95 Xu X, Ho W, Zhang X, Bertrand N, Farokhzad O. Cancer nanomedicine: from targeted delivery to combination therapy. Trends Mol. Med. 21(4), 223-232 (2015).

96 Byrne JD, Betancourt T, Brannon-Peppas L. Active targeting schemes for nanoparticle systems in cancer therapeutics. $A d v$. Drug Deliv. Rev. 60(15), 1615-1626 (2008).

97 Huang B, Abraham WD, Zheng Y, López SCB, Luo SS, Irvine DJ. Active targeting of chemotherapy to disseminated tumors using nanoparticle-carrying T cells. Sci. Transl. Med. 7(291), 291ra294-291ra294 (2015).

98 Gray BP, Mcguire MJ, Brown KC. A liposomal drug platform overrides peptide ligand targeting to a cancer biomarker, irrespective of ligand affinity or density. PLoS ONE 8(8), e72938 (2013).

99 Dobrovolskaia MA, Germolec DR, Weaver JL. Evaluation of nanoparticle immunotoxicity. Nat. Nanotechnol. 4(7), 411-414 (2009).

100 Deng ZJ, Liang M, Monteiro M, Toth I, Minchin RF. Nanoparticle-induced unfolding of fibrinogen promotes Mac-1 receptor activation and inflammation. Nat. Nanotechnol. 6(1), 39-44 (2011).

101 Prapainop K, Witter DP, Wentworth P Jr. A chemical approach for cell-specific targeting of nanomaterials: smallmolecule-initiated misfolding of nanoparticle corona proteins. J. Am. Chem. Soc. 134(9), 4100-4103 (2012).
102 Mahmoudi M, Sheibani S, Milani AS et al. Crucial role of the protein corona for the specific targeting of nanoparticles. Nanomedicine 10(2), 215-226 (2015).

103 Salvati A, Pitek AS, Monopoli MP et al. Transferrinfunctionalized nanoparticles lose their targeting capabilities when a biomolecule corona adsorbs on the surface. Nat. Nanotechnol. 8(2), 137-143 (2013).

104 Davis ME. The first targeted delivery of siRNA in humans via a self-assembling, cyclodextrin polymer-based nanoparticle: from concept to clinic. Mol. Pharm. 6(3), 659-668 (2009).

105 Varnamkhasti BS, Hosseinzadeh H, Azhdarzadeh $\mathrm{M}$ et al. Protein corona hampers targeting potential of MUC1 aptamer functionalized SN-38 core-shell nanoparticles. Int. J. Pharm. 494(1), 430-444 (2015).

106 Dai Q, Yan Y, Ang C-S et al. Monoclonal antibodyfunctionalized multilayered particles: targeting cancer cells in the presence of protein coronas. ACS Nano 9(3), 2876-2885 (2015).

107 Caracciolo G, Pozzi D, Capriotti AL et al. Cancer cell targeting of lipid gene vectors by protein corona. Nanotechnology 3, 354-357 (2012).

108 Monteiro-Riviere NA, Inman AO, Zhang L. Limitations and relative utility of screening assays to assess engineered nanoparticle toxicity in a human cell line. Toxicol. Appl. Pharmacol. 234(2), 222-235 (2009).

109 Balbus JM, Maynard AD, Colvin VL et al. Meeting report: hazard assessment for nanoparticles: report from an interdisciplinary workshop. Environ. Health Perspect. 115(11), 1654-1659 (2007).

110 Monteiro-Riviere NA, Inman AO. Challenges for assessing carbon nanomaterial toxicity to the skin. Carbon 44(6), 1070-1078 (2006).

111 Ruenraroengsak P, Novak P, Berhanu D et al. Respiratory epithelial cytotoxicity and membrane damage (holes) caused by amine-modified nanoparticles. Nanotoxicology 6(1), 94-108 (2012).

112 Ramasamy M, Das M, An SSA, Yi DK. Role of surface modification in zinc oxide nanoparticles and its toxicity assessment toward human dermal fibroblast cells. Int. J. Nanomedicine 9, 3707 (2014).

113 Yin H, Chen R, Casey PS, Ke PC, Davis TP, Chen C. Reducing the cytotoxicity of $\mathrm{ZnO}$ nanoparticles by a pre-formed protein corona in a supplemented cell culture medium. RSC Adv. 5(90), 73963-73973 (2015).

114 Liu Z, Chen K, Davis C et al. Drug delivery with carbon nanotubes for in vivo cancer treatment. Cancer Res. 68(16), 6652-6660 (2008).

115 Robinson JT, Welsher K, Tabakman SM et al. High performance in vivo near-IR $(>1 \mu \mathrm{m})$ imaging and photothermal cancer therapy with carbon nanotubes. Nano Res. 3(11), 779-793 (2010).

116 Kostarelos K. The long and short of carbon nanotube toxicity. Nat. Biotechnol. 26(7), 774-776 (2008).

117 Zhao Y, Xing G, Chai Z. Nanotoxicology: are carbon nanotubes safe? Nat. Nanotechnol. 3(4), 191-192 (2008). 
118 De Paoli SH, Diduch LL, Tegegn TZ et al. The effect of protein corona composition on the interaction of carbon nanotubes with human blood platelets. Biomaterials 35(24), 6182-6194 (2014).

119 Wang F, Yu L, Monopoli MP et al. The biomolecular corona is retained during nanoparticle uptake and protects the cells from the damage induced by cationic nanoparticles until degraded in the lysosomes. Nanomed. Nanotechnol. Biol. Med. 9(8), 1159-1168 (2013).

120 Kittler S, Greulich C, Diendorf J, Koller M, Epple M. Toxicity of silver nanoparticles increases during storage because of slow dissolution under release of silver ions. Chem. Mater. 22(16), 4548-4554 (2010).

121 Sies H, De Groot H. Role of reactive oxygen species in cell toxicity. Toxicol. Lett. 64, 547-551 (1992).

122 Manke A, Wang L, Rojanasakul Y. Mechanisms of nanoparticle-induced oxidative stress and toxicity. BioMed. Res. Int. 2013, 942916 (2013).

123 Minai L, Yeheskely-Hayon D, Yelin D. High levels of reactive oxygen species in gold nanoparticle-targeted cancer cells following femtosecond pulse irradiation. Sci. Rep. 3, 2146 (2013).

124 Gheshlaghi ZN, Riazi GH, Ahmadian S, Ghafari M, Mahinpour R. Toxicity and interaction of titanium dioxide nanoparticles with microtubule protein. Acta Biochim. Biophys. Sin. 40(9), 777-782 (2008).

125 Wangoo N, Suri CR, Shekhawat G. Interaction of gold nanoparticles with protein: a spectroscopic study to monitor protein conformational changes. Appl. Phys. Lett. 92(13), 133104 (2008).

126 Saptarshi SR, Duschl A, Lopata AL. Interaction of nanoparticles with proteins: relation to bio-reactivity of the nanoparticle. J. Nanobiotechnol. 11(1), 26 (2013).

127 Yoo SI, Yang M, Brender JR et al. Inhibition of amyloid peptide fibrillation by inorganic nanoparticles: functional similarities with proteins. Angew. Chem. Int. Ed. Engl. 50(22), 5110-5115 (2011).

128 Mirsadeghi S, Dinarvand R, Ghahremani MH et al. Protein corona composition of gold nanoparticles/nanorods affects amyloid beta fibrillation process. Nanoscale 7(11), 5004-5013 (2015).

129 Shannahan JH, Podila R, Aldossari AA et al. Formation of a protein corona on silver nanoparticles mediates cellular toxicity via scavenger receptors. Toxicol. Sci. 143(1), 136-146 (2014).

130 Yan Y, Gause KT, Kamphuis MM et al. Differential roles of the protein corona in the cellular uptake of nanoporous polymer particles by monocyte and macrophage cell lines. ACS Nano 7(12), 10960-10970 (2013).

131 Maiorano G, Sabella S, Sorce B et al. Effects of cell culture media on the dynamic formation of protein-nanoparticle complexes and influence on the cellular response. ACS Nano 4(12), 7481-7491 (2010).

132 Saptarshi SR, Duschl A, Lopata AL. Interaction of nanoparticles with proteins: relation to bio-reactivity of the nanoparticle. J. Nanobiotechnol. 11, 26 (2013).

133 Fadeel B. Clear and present danger? Engineered nanoparticles and the immune system. Swiss Med. Wkly 142, w13609 (2012).
134 Yan Y, Gause KT, Kamphuis MM et al. Differential roles of the protein corona in the cellular uptake of nanoporous polymer particles by monocyte and macrophage cell lines. ACS Nano 7(12), 10960-10970 (2013).

135 Lee YK, Choi EJ, Webster TJ, Kim SH, Khang D. Effect of the protein corona on nanoparticles for modulating cytotoxicity and immunotoxicity. Int. J. Nanomedicine 10, 97-113 (2015).

136 Salmon JE, Kapur S, Kimberly RP. Opsonin-independent ligation of $\mathrm{Fc}$ gamma receptors. The $3 \mathrm{G} 8$-bearing receptors on neutrophils mediate the phagocytosis of concanavalin A-treated erythrocytes and nonopsonized Escherichia coli. J. Exp. Med. 166(6), 1798-1813 (1987).

137 Leroux J-C, De Jaeghere F, Anner B, Doelker E, Gurny R. An investigation on the role of plasma and serum opsonins on the evternalization of biodegradable poly (D, L-lactic acid) nanoparticles by human monocytes. Life Sci. 57(7), 695-703 (1995).

138 Harashima H, Sakata K, Funato K, Kiwada H. Enhanced hepatic uptake of liposomes through complement activation depending on the size of liposomes. Pharm. Res. 11(3), 402-406 (1994).

139 Hulander M, Hong J, Andersson M et al. Blood interactions with noble metals: coagulation and immune complement activation. ACS Appl. Mater. Interfaces 1(5), 1053-1062 (2009)

140 Sim RB, Tsiftsoglou SA. Proteases of the complement system. Biochem. Soc. Trans. 32(Pt 1), 21-27 (2004).

141 Salvador-Morales C, Flahaut E, Sim E, Sloan J, Green ML, Sim RB. Complement activation and protein adsorption by carbon nanotubes. Mol. Immunol. 43(3), 193-201 (2006).

142 Hulander M, Lundgren A, Berglin M, Ohrlander M, Lausmaa J, Elwing H. Immune complement activation is attenuated by surface nanotopography. Int. J. Nanomedicine 6, 2653 (2011).

143 Yu K, Lai BF, Foley JH, Krisinger MJ, Conway EM, Kizhakkedathu JN. Modulation of complement activation and amplification on nanoparticle surfaces by glycopolymer conformation and chemistry. ACS Nano 8(8), 7687-7703 (2014).

144 Hubbell JA, Thomas SN, Swartz MA. Materials engineering for immunomodulation. Nature 462(7272), 449-460 (2009).

145 Bogart LK, Pourroy G, Murphy CJ et al. Nanoparticles for imaging, sensing, and therapeutic intervention. ACS Nano 8(4), 3107-3122 (2014).

146 Boraschi D, Duschl A (Eds). Nanoparticles and The Immune System: Safety and Effects. Academic Press, Waltham, MA, USA, 2013, 33-46 (2014).

147 Deng ZJ, Liang M, Monteiro M, Toth I, Minchin RF. Nanoparticle-induced unfolding of fibrinogen promotes Mac-1 receptor activation and inflammation. Nat. Nanotechnol. 6(1), 39-44 (2011).

148 Dobrovolskaia MA, Neun BW, Man S et al. Protein corona composition does not accurately predict hematocompatibility of colloidal gold nanoparticles. Nanomed. Nanotechnol. Biol. Med. 10(7), 1453-1463 (2014). 
149 Walkey CD, Olsen JB, Guo H, Emili A, Chan WC. Nanoparticle size and surface chemistry determine serum protein adsorption and macrophage uptake. J. Am. Chem. Soc. 134(4), 2139-2147 (2012).

150 Oldenborg P-A, Zheleznyak A, Fang Y-F, Lagenaur CF, Gresham HD, Lindberg FP. Role of CD47 as a marker of self on red blood cells. Science 288(5473), 2051-2054 (2000).

151 Rodriguez PL, Harada T, Christian DA, Pantano DA, Tsai RK, Discher DE. Minimal "Self" peptides that inhibit phagocytic clearance and enhance delivery of nanoparticles. Science 339(6122), 971-975 (2013).

152 Ashley CE, Carnes EC, Phillips GK et al. The targeted delivery of multicomponent cargos to cancer cells by nanoporous particle-supported lipid bilayers. Nat. Mater. 10(5), 389-397 (2011).

153 Toledano Furman NE, Lupu-Haber Y, Bronshtein T et al. Reconstructed stem cell nanoghosts: a natural tumor targeting platform. Nano Lett. 13(7), 3248-3255 (2013).

154 Muzykantov VR. Drug delivery by red blood cells: vascular carriers designed by mother nature. Expert Opin. Drug Deliv. 7(4), 403-427 (2010).

$155 \mathrm{Hu}$ CM, Zhang L, Aryal S, Cheung C, Fang RH, Zhang L. Erythrocyte membrane-camouflaged polymeric nanoparticles as a biomimetic delivery platform. Proc. Natl Acad. Sci. USA 108(27), 10980-10985 (2011).

156 Parodi A, Quattrocchi N, Van De Ven AL et al. Synthetic nanoparticles functionalized with biomimetic leukocyte membranes possess cell-like functions. Nat. Nanotechnol. 8(1), 61-68 (2013).
157 Hu C-MJ, Fang RH, Wang K-C et al. Nanoparticle biointerfacing by platelet membrane cloaking. Nature 526(7571), 118-121 (2015).

158 Hirlekar R, Patel P, Dand N, Kadam V. Drug loaded erythrocytes: as novel drug delivery system. Curr. Pharm. Des. 14(1), 63-70 (2008).

159 Hu C-MJ, Zhang L, Aryal S, Cheung C, Fang RH, Zhang L. Erythrocyte membrane-camouflaged polymeric nanoparticles as a biomimetic delivery platform. Proc. Natl Acad. Sci. USA 108(27), 10980-10985 (2011).

160 Fang RH, Hu C-MJ, Luk BT et al. Cancer cell membranecoated nanoparticles for anticancer vaccination and drug delivery. Nano Lett. 14(4), 2181-2188 (2014).

161 Corbo C, Parodi A, Evangelopoulos M et al. Proteomic profiling of a biomimetic drug delivery platform. Curr. Drug Targets 16(13), 1540-1547 (2015)

- The proteomic characterization of biomimetic nanoparticles (i.e., leuko-like vector: mesopourous silica nanoparticles coated with leukocytes plasma membranes) is discussed. One of the first papers focused on the proteomic content of cell membranes coating nanoparticles.

162 Aimanianda V, Bayry J, Bozza S et al. Surface hydrophobin prevents immune recognition of airborne fungal spores. Nature 460(7259), 1117-1121 (2009).

163 Sarparanta M, Bimbo LM, Rytkonen J et al. Intravenous delivery of hydrophobin-functionalized porous silicon nanoparticles: stability, plasma protein adsorption and biodistribution. Mol. Pharm. 9(3), 654-663 (2012). 